\title{
Current Trends of Emergence and Spread of Vancomycin-Resistant Enterococci
}

\author{
Guido Werner \\ Robert Koch-Institute, Wernigerode Branch, \\ Germany
}

\section{Introduction}

Enterococci are intestinal colonizers in many mammals including man, birds, reptiles and even invertebrates and are also found in diverse environments such as sewage, soil and water. They have been used for decades for food fermentation and preservation due to their metabolic properties and their capability to produce bacteriocins active against food contaminants like Listeria. Within the last two decades enterocococci became prominent as important hospital-acquired pathogens. Isolates of Enterococcus faecalis and E. faecium are the third- to fourth-most prevalent nosocomial pathogen worldwide. Among ICU-acquired bloodstream infections enterococci ranked second most prevalent according to data from an European project on Healthcare-Associated Infections. ${ }^{1}$ Infections with enterococci hit the very young, the elderly and immuno-compromised patients and are thus mostly restricted to specific hospital wards like haemato-oncological, paediatric, and intensive care units. The growing number of patients at risk of acquiring an enterococcal infection is linked to an aging population, especially in industrialised countries, and an increasing application of invasive medical treatment options.

Non-susceptibility to glycopeptide antibiotics like vancomycin and teicoplanin is the key resistance characteristic in enterococci. Acquired resistance to vancomycin is mediated by various mechanisms (types VanA/B/D/E/G/L; Table 1); the vanA and vanB resistance genotypes are by far the most prevalent. The reservoir for vanA- and vanB-type resistance in humans is in E. faecium (Christiansen et al., 2004; Willems and van Schaik W. 2009; Johnson et al., 2010; Willems et al., 2011). Consequently, increasing rates of VRE in several European countries are due to an increasing prevalence of vancomycin-resistant E. faecium (VREfm). Ampicillin- and/or vancomycin-resistant E. faecalis (VREfs) are still rare. Defined clonal groups of E. faecium show an enhanced capacity to disseminate in the nosocomial setting and are thus called epidemic or hospital-acquired (Top et al., 2008a; Willems and van Schaik W. 2009; EARSS 2009; Willems et al., 2011). These strains can be assigned to distinct clonal groups or complexes based on various molecular typing schemes and subsequent phylogenetic analyses (Willems and van Schaik W. 2009; Willems et al., 2011). Hospitalacquired E. faecium are mostly ampicillin-resistant, partly high-level ciprofloxacin-resistant

\footnotetext{
${ }^{1}$ http://www.ecdc.europa.eu/en/publications/Publications/1011_SUR_Annual_Epidemiological_Rep ort_on_Communicable_Diseases_in_Europe.pdf
} 
and possess additional genomic content (accessory genome), which includes putative virulence traits such as a gene for an enterococcal surface protein, esp, genes encoding different cell wall-anchored surface proteins, a putative hyaluronidase gene, $h y l_{\mathrm{Efm}}$ and a gene encoding a collagen-binding protein, acm (Willems et al., 2001; Leavis et al., 2007; Hendrickx et al., 2007; Hendrickx et al., 2008; Heikens et al., 2008; Sillanpaa et al., 2008; Nallapareddy et al., 2008; Hendrickx et al., 2009; van Schaik et al., 2010; Laverde Gomez et al., 2010; van Schaik and Willems 2010).

\section{Natural antibiotic resistances in E. faecium and E. faecalis}

Besides their huge arsenal of insusceptibilities to physicochemical and environmental stresses (Murray 1990; Facklam et al., 2002) E. faecalis and E. faecium possess a broad spectrum of natural antibiotic resistances (Klare et al., 2003; Arias and Murray 2008).

All enterococci are naturally (intrinsically) resistant to the following agents: semisynthetic penicillins (e.g., oxacillin), cephalosporins of all classes, monobactams and polymyxins. Aminoglycosides show insusceptibility at a low level, most probably due to a reduced uptake. At least, isolates of E. faecalis and E. faecium show clindamycin insusceptibility; in $E$. faecalis this is known to be associated with the expression of an ABC porter designated Lsa (Singh et al., 2002; Singh and Murray 2005). Presence of Lsa also mediates resistance to streptogramin A which in the consequence also leads to resistance to the streptogramin A/B combination (quinupristin/dalfopristin). Insusceptibility to fluoroquinolones, for instance to ciprofloxacin, is most probably associated with expression of chromosomal qnr homologues (functionally proven only for E. faecalis, (Arsene and Leclercq 2007; Rodriguez-Martinez et al., 2008). Isolates of E. faecalis are also resistant to mupirocin, a property that can be used to differentiate them from other enterococcal species. Although not reaching the level of what is defined as resistance, penicillins are generally less active against enterococci than against streptococci and in addition, E. faecium is less susceptible than E. faecalis (Murray 1990).

\section{Acquired antibiotic resistances in E. faecium and E. faecalis}

The already tremendous spectrum of intrinsic insusceptibilities of E. faecalis and E. faecium is accompanied by the potential to acquire resistance to all antimicrobial drugs available (Tenover and McDonald 2005; Rice 2006). Therapeutically important are resistance properties against penicllin/ampicillin, gentamicin/streptomycin and glycopeptides (vancomycin/teicoplan) as well as resistances against antibiotics of last resort quinupristin/dalfopristin [E. faecium], linezolid and tigecycline (maybe also daptomycin).

\subsection{Penicillin resistance}

Penicillin resistance in E. faecalis is rare and if occurring linked to certain clonal lineages expressing beta-lactamases similar or identical to the $S$. aureus penicillinase (Nallapareddy et al., 2005; Ruiz-Garbajosa et al., 2006; McBride et al., 2007). Penicillin resistance in E. faecium is mediated via point mutations in the housekeeping $p b p 5$ gene leading to reduced penicillin binding to the expressed protein (Jureen et al., 2004; Rice et al., 2004; Rice et al., 2009). Mutated pbp5' was also found as an integral part of conjugative transposons, like Tn5382, thus encoding transferable ampicillin and VanB-type vancomycin resistance (Carias et al., 
1998; Valdezate et al., 2009). Results of a recent study suggested additional factors independent from pbp5' contributing to acquired ampicillin resistance in hospital strains of E. faecium (Galloway-Pena et al., 2011).

\subsection{Aminoglycoside resistance}

Only the two aminoglycosides gentamicin and streptomycin exemplify a synergistic effect when given in combination with a cell-wall active agent like a penicillin or a glycopeptide (Murray 1990). Certain aminoglycoside-modifying enzymes mediate acquired high-level gentamicin and streptomycin resistance in E. faecalis and E. faecium. The aac6'-aph2" (aac(6')-Ie$\left.a p h\left(2^{\prime \prime}\right)-I a\right)$ gene encodes a bifunctional enzyme encoding high-level resistance to all aminoglycosides except streptomycin (Horodniceanu et al., 1979). It is the most prevalent form of acquired gentamicin resistance in both species and associated with homologues of transposon Tn4001/Tn5281 flanked by two copies of IS256 and most probably originating from staphylococci (Casetta et al., 1998; Hallgren et al., 2003; Saeedi et al., 2004). Gentamicin resistance may also be encoded by other determinants such as aac(6')-Ii, aph(2")-Ie, and ant(6)Ia (Jackson et al., 2004; Jackson et al., 2005; Zarrilli et al., 2005; Mahbub et al., 2005). High-level streptomycin resistance is encoded by the aadE gene which is an integral part of a multiresistance gene cluster aadE-sat4-aphA encoding streptomycin-streptothricin-kanamycin resistance. The sat4 gene encoding streptothricin (nourseothricin) resistance has first been described in Campylobacter coli (Jacob et al., 1994; Bischoff and Jacob 1996). In staphylococci the aadE-sat4-aphA gene cluster is flanked by two copies of IS1182 constituting transposon Tn5405 (Derbise et al., 1996; Derbise et al., 1997). The aadE-sat4-aphA gene cluster is widespread among many Gram-positive genera and it remains to be speculative where this gene clusters originates from and subsequently spread to other bacteria. Strikingly, in S. aureus the sat4 gene possesses a point mutation within the coding region leading to a pre-mature STOPP codon; whereas it is complete and functional in C. coli and enterococci encoding detectable streptothricin (nourseothricin) insusceptibility (Schwarz et al., 2001; Werner et al., 2001a; Teuber et al., 2003; Werner et al., 2003a).

\subsection{Fluoroquinolone resistance}

The targets of fluoroquinolones are topoisomerases II and IV, and mutational changes among genes encoding mainly subunits $\mathrm{A}$ and to a lesser extent also subunits $\mathrm{B}$ are associated with increased MICs to ciprofloxacin and other fluoroquinolones (Hooper 2002; Jacoby 2005). Topoisomerase II (DNA gyrase) appears to be the primary target in Gramnegative bacteria and topoisomerase IV is the primary target in Gram-positive bacteria. Corresponding in vitro selection models were also described for enterococci; however, results are somehow conflicting regarding the primary target in Enterococcus spp. and the necessity of specific mutations in one or both A subunit genes to confer what is specified as high-level ciprofloxacin resistance (Onodera et al., 2002; Oyamada et al., 2006a; Oyamada et al., 2006b). Molecular studies with high-level ciprofloxacin-resistant clinical isolates revealed mutations in both A subunits associated with different levels of ciprofloxacin resistance, whereas mutations in $g y r B$ and parE alleles were only infrequently found (Woodford et al., 2003; Leavis et al., 2006; Valdezate et al., 2009; Werner et al., 2010a). 


\subsection{Resistance to macrolides, lincosamides and streptogramin $B\left(M L S_{B}\right)$}

Resistance to $M_{L} S_{B}$ antibiotics is encoded by the widespread erm(B) gene and only occasionally via erm(A) or erm(C)(Roberts et al., 1999). Erm ("erythromycin resistance methylases") confer resistance by modifying nucleotide A2058 of the bacterial $23 \mathrm{~S}$ rRNA (methylation) leading to resistance to $\mathrm{MLS}_{\mathrm{B}}$ antibiotics. The resistance phenotype is partly overlapping with the spectrum of natural resistances in Enterococcus (lincosamides); however, erm genes are widespread among other Gram-positive bacteria such as streptococci, staphylococci, lactococci and lactobacilli where the corresponding resistance phenotype has been studied in detail (Shaw and Clewell 1985; Novick and Murphy 1985). Naturally, the expression of erm genes is induced with low levels of 14-membered macrolides (i.e. erythromycin) and results in cross-resistance to all 14-, 15- and 16-membered macrolides, lincosamides and streptogramin B antibiotics. Induction results from translational relief of attenuation (Horinouchi and Weisblum 1980). Constitutive expression of $\operatorname{erm}(\mathrm{A})$ and $\operatorname{erm}(\mathrm{C})$ in staphylococci results from deletions, duplications, and point mutations in the region of the leader peptide, and is selected for by the use of non-inducing antibiotics (Werckenthin et al., 1999; Werckenthin and Schwarz 2000; Schmitz et al., 2001). In enterococci $\mathrm{erm}$ (B) is constitutively expressed (Werner et al., 2000; Werner et al., 2002; Martel et al., 2003); however, corresponding modifications in the leader peptide could not be linked unambiguously to cause the corresponding phenotype in wildtype isolates (Rosato et al., 1999; Werner et al., 2002). Recent in vitro studies have linked point mutations rather than deletions and duplications to a corresponding $\operatorname{erm}(\mathrm{B})$ constitutive phenotype in enterococci (Min et al., 2008). The erm(B) determinant is widespread among enterococci, especially $E$. faecium and $E$. faecalis and is part of many multi-resistance plasmids and often linked to Tn1546-like vanA elements (Aarestrup et al., 2000a; Borgen et al., 2002; Werner et al., 2003a; Werner et al., 2003b; Manson et al., 2003b; Werner et al., 2006; Laverde Gomez et al., 2010). Another mechanism mediating macrolide (and streptogramin B) resistance is conferred by the msrA-C genes (Reynolds et al., 2003; Kerr et al., 2005) whereas $m s r C$ is discussed as a species-specific property in E. faecium (Singh et al., 2001; Werner et al., 2001b) shown to encode erythromycin and clarithromycin resistance when expressed in S. aureus (Reynolds and Cove 2005). Staphylococcal efflux pumps of the Vgb-type encoding for streptogramin type B resistance remain extremely rare among E. faecium (Werner et al., 2002).

\subsection{Streptogramin A resistance}

Two types of acetyltransferases VatD and VatE mediate resistance to streptogramin A in enterococci, mainly E. faecium (Werner et al., 2002). E. faecalis is naturally resistant to streptogramin A and thus the synergism of the A and B streptogramin combination is abolished (Werner et al., 2002; Singh et al., 2002). However, a few studies described also vat genes to be prevalent among related lactic acid bacteria (Gfeller et al., 2003) and E. faecalis isolates (Simjee et al., 2002; Jones and Deshpande 2004). Their relevance for increasing the level of streptogramin resistance in E. faecalis is unclear; nevertheless, resistance determinants could further spread to E. faecium and other enterococcal species thus rendering their level of streptogramin susceptibility. Staphylococcal efflux pumps of the Vga-type encoding for streptogramin type A resistance remain unknown to E. faecium (Werner et al., 2002); except for a single Korean E. faecium isolate described recently harbouring streptogramin A resistance genes vgaD and vat $G$ on a plasmid fragment encoding for a new efflux pump type and a new streptogramin acetyltransferase, respectively (Jung et al., 2010). 


\subsection{Tetracycline resistance}

Resistance to tetracyclines is mediated via different acquired tet genes encoding proteins mediating (a) ribosomal protection $[\operatorname{tet}(\mathrm{O}) /(\mathrm{M})(\mathrm{S})]$ or efflux $[\operatorname{tet}(\mathrm{K}) /(\mathrm{L})][($ Roberts 2005). Most wide-spread among enterococci and best studied are elements containing tet(M). The tet(M) gene mostly resides on conjugative transposons of the Tn916/Tn1545- or Tn5397types that possess a very wide host range and can exist in several functional copies thus supporting flexibility and recombinational events within a given bacterial genome (Thal et al., 1997; Roberts et al., 2001; Agerso et al., 2006; Rice et al., 2007; Boguslawska et al., 2009; de Vries et al., 2009; Rice et al., 2010; Roberts and Mullany 2011).

\subsection{Linezolid resistance}

Linezolid is a synthetic oxazolidinone antibiotic of last resort active against multi- and vancomycin-resistant enterococci. It inhibits first steps of ribosome formation [108]. Although being fully synthetic, resistance is selected under therapy and is in relation to the duration of treatment (Prystowsky et al., 2001; Pai et al., 2002; Ruggero et al., 2003; Seedat et al., 2006). However, a few reports documented resistance detection independent from linezolid treatment (Rahim et al., 2003; Bonora et al., 2006). Resistance results from point mutations in 23S rRNA, preferably at position 2576 (G > T)(Sinclair et al., 2003; Werner et al., 2004; Qi et al., 2006; Werner et al., 2007a) and the level of resistance is dependent on the number of mutated alleles per genome (Marshall et al., 2002; Lobritz et al., 2003; BourgeoisNicolaos et al., 2007; Boumghar-Bourtchai et al., 2009). Once established, resistance levels quickly arise due to recombinational exchange of mutated $23 \mathrm{~S}$ rDNA alleles under selective pressure (Willems et al., 2003; Boumghar-Bourtchai et al., 2009). In Staphylococcus, a Cfr methylase is able to modify $23 \mathrm{~S}$ rRNA at position A2503 leading to cross-resistance to a number of antibiotics including oxazolidinones (Toh et al., 2007); however, the corresponding $c f r$ gene has not been described in enterococci so far.

\subsection{Tigecycline resistance}

Tigecycline is a member of a new tetracycline antibiotic class containing a 9-tertbutylglycylamido group named glycylcyclines and acts similar to tetracyclines by inhibiting protein biosynthesis. Tigecycline is active against many Gram-negative and Gram-positive bacteria including isolates of Enterococcus. International surveillance studies revealed in general potent in vitro activity; non-susceptible isolates are very rare. A single resistance mechanism linked to an overexpression of an oxygen- and flavin-dependent monooxygenase, TetX, originating from anaerobic bacteria of the genus Bacteroides was described (Moore et al., 2005). A single tigecycline-non-susceptible E. faecalis isolate was reported recently and investigated in greater details; however, the underlying resistance mechanism could not been determined (Werner et al., 2008b).

\subsection{Daptomycin resistance}

Daptomycin is a cyclic lipopeptide antibiotic disrupting cell membrane composition, function and permeability (Straus and Hancock 2006a; Straus and Hancock 2006b). Daptomycin is active against many Gram-positive bacteria. Its in vivo activity against enterococci is still debatable (Canton et al., 2010). Daptomycin resistance developed under 
therapy in bacteria other than enterococci and was multifactorial and is still not understood completely (Fischer et al., 2011).

\subsection{Vancomycin resistance}

Glycopeptide antibiotics consist of a peptide ring to which several sugars are covalently linked. They are produced by actinomycetes and have a quite complex structure. This voluminous structure prevents penetration through the outer membrane of Gram-negative bacteria limiting their therapeutic use only to treat infections with Gram-positive bacteria. Two naturally produced antibiotics have been introduced into antimicrobial treatment, vancomycin and teicoplanin; the latter only outside North-America. Three semisynthetic progenitors designated as lipoglycopeptides or glycolipopeptides (dalbavancin, telavancin, oritavancin) are promising new candidate drugs partially active against multi-resistant and also vancomycin-(intermediate)resistant bacteria (Zhanel et al., 2010a). The primary target of glycopeptides is the C-terminal D-Alanyl-D-Alanine ending of the peptide side chain of the enterococcal peptidoglycan cell wall precursor. Due to steric hindrance the cell wall synthesis enzymes like transglycosylases, transpeptidases and D,D-carboxypeptidases cannot access their target and cell wall synthesis stops. Vancomycin and related glycopeptides act as dimers (Batchelor et al., 2010).

Enterococci were the first pathogens that showed acquired vancomycin resistance and corresponding strains have been isolated from clinical samples from patients in Europe and the USA in the late 1980s (Leclercq et al., 1988; Leclercq et al., 1989; Sahm et al., 1989). The corresponding resistance phenotypes which included inducible resistance to all known glycopeptides or vancomycin only were designated VanA and VanB, respectively. In fact, the structure, localization and functional interplay of the resistance determinants arranged in specific transposable elements in enterococci has been studied with some of the first identified VRE: E. faecium BM4147 (vanA genotype) from France (Leclercq et al., 1988) and E. faecalis V583 (vanB genotype) from the USA (Sahm et al., 1989). The latter became prominent as the first Enterococcus isolate that has been completely sequenced (Paulsen et al., 2003). To date eight types of acquired vancomycin resistance in enterocooci are known having a related mechanism of resistance and a similar resistance gene cluster composition but show major differences in prevalence (Table 1 and Figure 1; see recent reviews for details: (Courvalin 2005; Courvalin 2006; Werner et al., 2008a; Werner et al., 2008c). Worldwide by far the most prevalent type is vanA followed by vanB. The vanA gene is an integrated part of Tn1546 or derivatives of this transposon which are usually located on transferable plasmids (Werner et al., 2008a; Werner 2011). vanB could be subdivided into three different allele types (vanB1-3) with vanB-2 the most prevalent type worldwide. The vanB alleles are part of Tn1547 or the conjugative transposon Tn1549/5382 which are mainly chromosomally located and less frequently, on plasmids (Werner et al., 2006; Zheng et al., 2009; Hegstad et al., 2010; Bjorkeng et al., 2011). The main clinical relevant reservoir of vanA and vanB elements is in $E$. faecium, at least in Europe, Northern and Latin America and Southeast Asia, although they have also been observed occasionally in other enterococcal species (see Table 1 and below)(Zirakzadeh and Patel 2005; Werner et al., 2008a; Werner 2011).

\section{The van alphabet in Enterococcus spp.}

Non-susceptibility to glycopeptide antibiotics like vancomycin and teicoplanin is the key resistance characteristic in enterococci. Acquired resistance to vancomycin is mediated by 


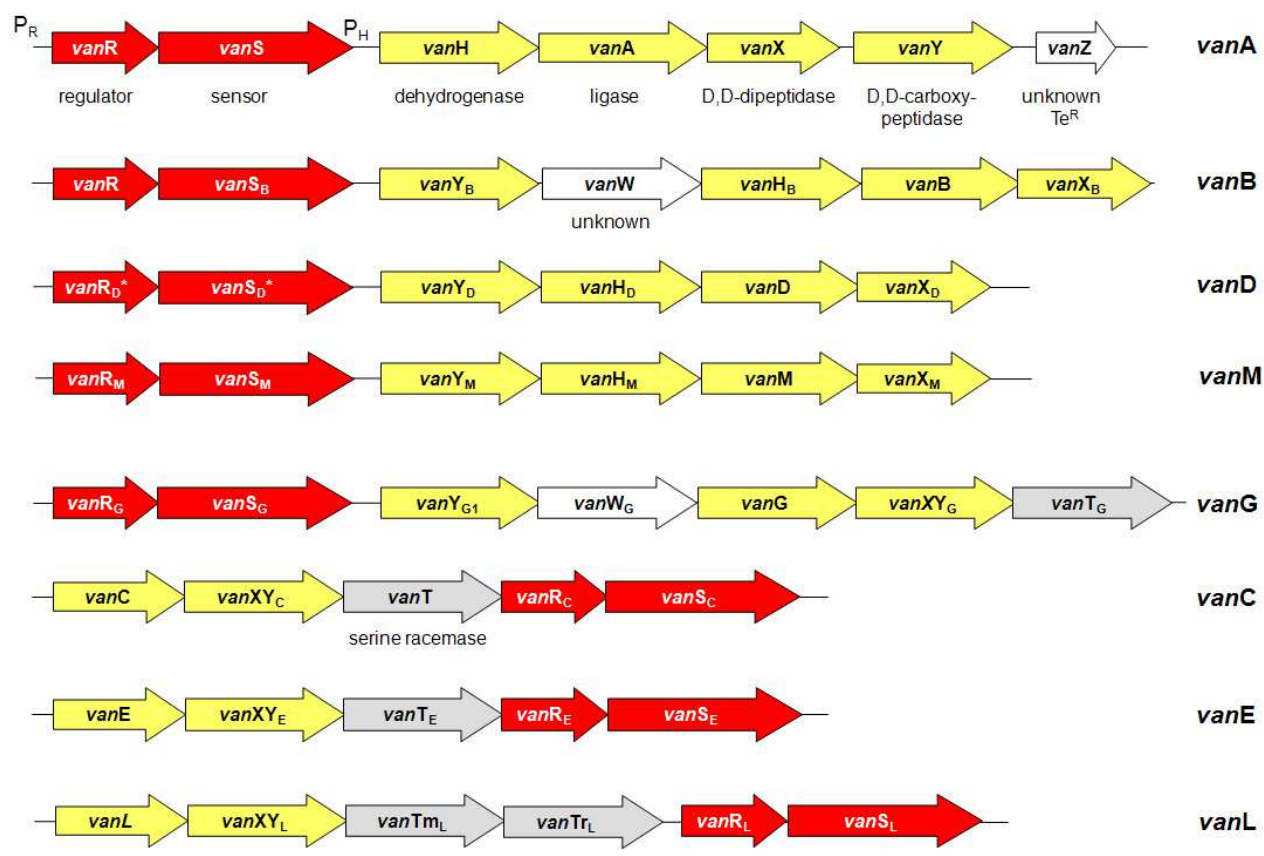

The image of the van $C$ cluster from naturally vancomycin-resistant $E$. gallinarum and $E$. casseliflavus were introduced for reasons of comparability. Arrows indicate genes and arrowheads show the direction of transcription. Colour codes represent functional groups: red, two-component regulatory system; yellow, core genes essential for resistance expression; grey, serine racemase; white, additional or unknown function. Arrow lengths are according to the size of the genes but are not drawn to scale. * denotes point mutations leading to constitutive expression of the VanD-type resistance. For further details see main text or references given there. $\mathrm{P}_{\mathrm{R}}$ and $\mathrm{P}_{\mathrm{H}}$ are promoters preceding van $\mathrm{R}$ and $v a n H$, respectively. $\mathrm{Te}^{\mathrm{R}}$, gene associated with decreased teicoplanin susceptibility. For references see legend of Table 1.

Fig. 1. Structure and composition of the vancomycin resistance clusters vanA-M (see also Table 1). Types vanA, vanB, vanD and vanM encode D-Ala-D-Lac mediated resistance; types van $C$, vanE, vanL and $\operatorname{van} G$ (also $\operatorname{van} N$, not shown) encode D-Ala-D-Ser mediated resistance (see text and Table for details)

various mechanisms (types VanA/B/D/E/G/L/M/N; Table 1); the vanA and vanB resistance genotypes are by far the most prevalent worldwide. Isolates of E. gallinarum and E. casseliflavus (= E. flavescens) are naturally (intermediate-)resistant to vancomycin at low levels (MIC $=8 \mathrm{mg} / \mathrm{L}$ ) by a so-called VanC-1/-2 type.

\subsection{The VanA resistance type}

The original vanA gene cluster contains nine genes which are arranged in a transposon structure (Arthur et al., 1993)(Fig. 1). It is flanked by two incomplete inverted repeats and possesses two coding sequences located at the left end (ORFs 1 and 2 not shown in Fig. 1). Their putative proteins show similarity with resolvases and transposases of various transposons or plasmids. The entire element is 10,981 bp and designated Tn1546, belonging to transposons of the Tn3-family. 
Expression of VanA type vancomycin resistance in enterococci is inducible via a complex mechanism. The consequences of a prevented cell wall synthesis are sensed by an as yet still unknown mechanism via a membrane-associated, Tn1546-encoded protein VanS possessing a histidine kinase in its cytoplasmatic C-terminus. The histidine kinase function of the VanS protein is activated by autophosphorylation and the corresponding phosphate moiety is transferred to a cytoplasmic response regulator called VanR also encoded on Tn1546. Phosphorylated VanR functions as a transcriptional activator binding at two promoters $P_{R}$ and $P_{H}$ in the vanA resistance gene cluster (Arthur et al., 1997). This leads to the expression of two transcripts of genes that are arranged in an operon structure and that are transcribed unidirectional: the vanRS genes themselves and the gene cluster vanHAXYZ (Fig. 1). The proteins VanH, VanA and VanX possess essential functions for the expression of glycopeptide resistance whereas VanY encodes a D,D-carboxypeptidase contributing to elevated resistance levels and a VanZ protein of unknown function but contributing by an unknown mechanism to low-level teicoplanin resistance (Fig. 2)(Arthur and Quintiliani, Jr. 2001). VanA type vancomycin resistance is mediated via an alternative pathway synthesizing cell wall precursors ending in D-Alanyl-D-Lactat (D-Ala-D-Lac) showing reduced glycopeptide binding and down-shifting of the regular cell wall synthesis by housekeeping enzymes (Fig. 1)(Arthur and Quintiliani, Jr. 2001).

Studies about characterizing the structure of vanA gene clusters in enterococci of different ecological and geographical sources displayed a great variety of point mutations, deletions (in/of non-essential genes), and insertions of additional DNA (mainly IS elements) leading to modified and fragmented Tn1546 structures. This can be demonstrated in a phylogenetic tree of relatedness exemplifying elements typically identified in US hospital VRE, poultry VRE, pig/human commensal VRE, etc. (Willems et al., 1999; Werner et al., 2006). Typing of vanA gene clusters allows elucidating ways of spread of vancomycin resistance either via clonal spread of VRE or via horizontal gene transfer between different enterococci (Park et al., 2007; Sletvold et al., 2010).

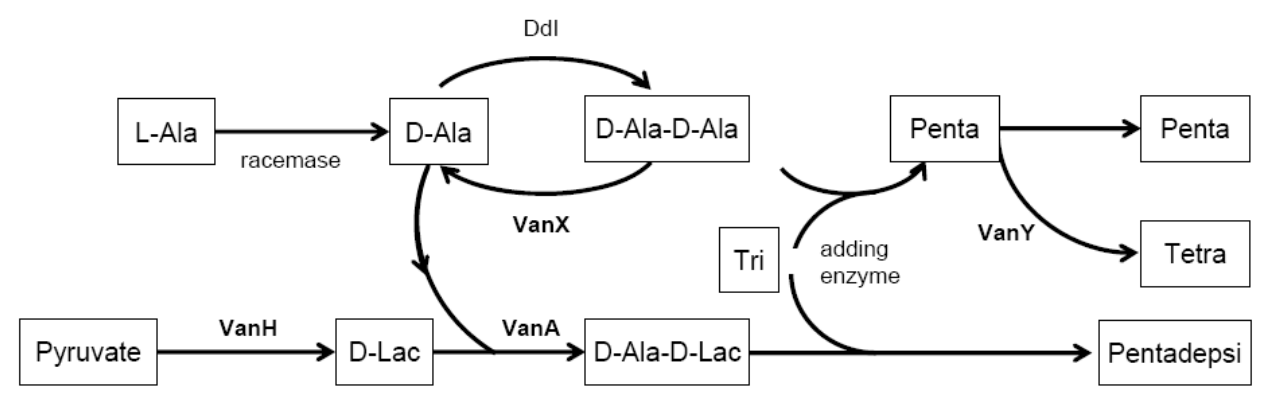

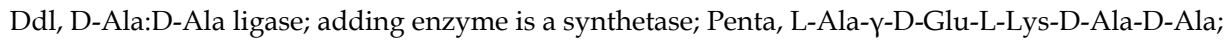
Pentadepsi, L-Ala- $\gamma$-D-Glu-L-Lys-D-Ala-D-Lac; Tetra, L-Ala- $\gamma$-D-Glu-L-Lys-D-Ala; Tri, L-Ala- $\gamma-D-G l u-$ L-Lys. Penta, Tetra, Tri, Pentadepsi represent amino acid side chains linked to the enterococcal peptidoglycan disaccharide precursor N-acetyl-glucosamin-N-acetyl-muramic acid. Resistance enzymes encoded by the vanA cluster are shown in bold. [Figure adapted from (Courvalin 2006)].

Fig. 2. VanA-type glycopeptide resistance. Synthesis of an alternative, vancomycinresistant pentadepsipeptide peptidoglycan precursor in VanA-type resistant strains. 


\subsection{The VanB resistance type}

The typical VanB phenotype is characterized by inducible moderate vancomycin resistance levels (MICs of $8-64 \mathrm{mg} / \mathrm{L}$ ) and teicoplanin susceptibility. vanB isolates with high-level vancomycin resistance have also been identified. Differences in the $\operatorname{van} B$ gene were found and three different $\operatorname{van} B$ ligase alleles were assigned which can be used for subtyping [vanB1/-2/-3; (Dahl et al., 2003; Werner et al., 2006)]. However, the different vanB genotypes did not correlate with the level of vancomycin resistance. Despite being slightly different in nucleotide composition, the vanB cluster types 1 to 3 all resemble the core structure of the vanA gene cluster (Fig. 1). Genes of related composition and function are arranged in a similar manner, an equivalent to van $Z$ is lacking and an additional gene vanW of unknown function was found. Genes encoding the two-component regulatory system $v a n R_{B} S_{B}$ are only distantly related to their Tn1546 counterparts and regulation of gene expression is different, because only vancomycin, but not teicoplanin, is an inducer of the vanB cluster. The entire transposon backbone of van $B$ clusters is different to van $A$; distinct van $B$ cluster types are either flanked by certain IS elements or an integral part of larger mobile and/or conjugative elements that may be composed of several individual elements [Tn1547, Tn1549, Tn5382-like, Tnvamp; (Carias et al., 1998; Dahl and Sundsfjord 2003; Werner et al., 2006; Launay et al., 2006; Valdezate et al., 2009; Lopez et al., 2009)]. The conjugative vanB transposon Tn1549 or its backbone is widely prevalent among vanB type enterococci and related Gram-positive bacteria such as Clostridium spp. (see chapter 5;(Launay et al., 2006; Tsvetkova et al., 2010)). Conjugative transposons have been known for a long time in Enterococcus and Bacteroides and were lately also identified in Gram-negatives. They have an important function for a wide distribution of (resistance) genes across species and genus barriers and for genomic rearrangements in bacteria in general (Rice et al., 2005; Roberts and Mullany 2009; Rice et al., 2010; Roberts and Mullany 2011).

Whereas teicoplanin does not induce VanB type resistance, constitutively resistant mutants quickly arose in vivo during therapy or in vitro after teicoplanin challenge (Baptista et al., 1999; Kawalec et al., 2001a; Kawalec et al., 2001b; San Millan et al., 2009b). Accordingly, teicoplanin treatment is not recommended for eradicating VanB VRE infections despite a correspondingly suggestive diagnostic result (teicoplanin susceptibility).

Expression via the VanB type two-component regulatory system $\operatorname{VanR}_{B} S_{B}$ is differently regulated in various Gram-positive hosts. Naturally occurring VanB type Streptococcus bovis/gallolyticus isolates retained the VanB phenotype inducible by vancomycin only (Poyart et al., 1997; Mevius et al., 1998). Genetic constructs of vanB cluster elements in a Bacillus subtilis background did not show an inducible phenotype since $V_{a n} S_{B}$ was active also without vancomycin addition (San Millan et al., 2009a). In addition, it was shown that the phosphorylated regulator $\mathrm{VanR}_{\mathrm{B}} \mathrm{P}$ - was capable of binding to a number of promoter regions and thus controlling expression of genes commonly regulated by response regulators.

\subsection{The VanC resistance type}

The two motile species E. gallinarum and E. casseliflavus possess an intrinsic resistance to vancomycin at a low level designated VanC-1 and VanC-2, respectively. The corresponding vanC-type ligase gene possessed minor sequence diversity resulting in the two described subtypes vanC-1 and vanC-2 (Courvalin 2005; Courvalin 2006). The formerly third species E. 
flavescens described as possessing a supposed vanC-3 gene was merged recently with the species E. casseliflavus (Naser et al., 2006b) thus leading to two subtypes of E. casseliflavus with slightly different vanC-2/-3 subtype variants. Recently, another subtype vanC-4 was described in another E. casseliflavus isolate with $93-95 \%$ nucleotide identity with vanC-2/-3 (Naser et al., 2006a).

\begin{tabular}{|c|c|c|c|c|c|c|c|c|}
\hline $\begin{array}{l}\text { Resistance } \\
\text { phenotype }\end{array}$ & VanA & VanB $^{2}$ & VanD $^{2}$ & VanE & VanG $^{2}$ & VanL & VanM & VanN $^{4}$ \\
\hline $\begin{array}{r}\text { MIC vancomycin } \\
\text { in } \mu \mathrm{g} / \mathrm{ml}\end{array}$ & $16-1000$ & $\begin{array}{c}4-32 \\
(-1000)\end{array}$ & $16-512$ & $8-32$ & 16 & 8 & $>256$ & 16 \\
\hline $\begin{array}{r}\text { MIC }_{\text {teicoplanin }} \\
\text { in } \mu \mathrm{g} / \mathrm{ml}\end{array}$ & (4-) 16 - 512 & $0,5-1$ & $0,5-64$ & 0,5 & 0,5 & S & $0.75 / 96^{3}$ & S \\
\hline expression & inducible & inducible & constitutive & inducible & inducible & inducible & inducible & $?$ \\
\hline ligase & $\begin{array}{l}\text { D-Ala-D- } \\
\text { Lac }\end{array}$ & $\begin{array}{c}\text { D-Ala-D- } \\
\text { Lac }\end{array}$ & $\begin{array}{l}\text { D-Ala-D- } \\
\text { Lac }\end{array}$ & \begin{tabular}{|c|} 
D-Ala-D- \\
Ser
\end{tabular} & $\begin{array}{l}\text { D-Ala-D- } \\
\text { Ser }\end{array}$ & $\begin{array}{l}\text { D-Ala-D- } \\
\text { Ser }\end{array}$ & \begin{tabular}{|c|} 
D-Ala-D- \\
Lac
\end{tabular} & \begin{tabular}{|c|} 
D-Ala-D- \\
Ser
\end{tabular} \\
\hline localization & $\begin{array}{l}\text { plasmid/ } \\
\text { chrom. }\end{array}$ & $\begin{array}{l}\text { chrom./ } \\
\text { plasmid }\end{array}$ & chrom. & chrom. & chrom. & chrom.? & plasmid & ? \\
\hline \begin{tabular}{|r|} 
transferable by \\
conjugation
\end{tabular} & $+/-$ & $+/-$ & - & - & + & - & + & ? \\
\hline $\begin{array}{r}\text { Distribution } \\
\text { among } \\
\text { enterococcal } \\
\text { species }\end{array}$ & $\begin{array}{c}\text { E. faecium } \\
\text { E. faecalis } \\
\text { E. durans } \\
\text { E. hirae } \\
\text { E. } \\
\text { gallinarum }{ }^{1} \\
\text { E. } \\
\text { casseliflavus }^{1} \\
\text { E. raffinosus } \\
\text { E. avium } \\
\text { E. mundtii }\end{array}$ & $\begin{array}{c}\text { E. faecium } \\
\text { E. faecalis } \\
\text { E. durans } \\
\text { E. } \\
\text { gallinarum } \\
1\end{array}$ & \begin{tabular}{|c} 
E. faecium \\
E. faecalis \\
E. raffinosus \\
E. \\
gallinarum $^{1}$
\end{tabular} & E. faecalis & E. faecalis & E. faecalis & E. faecium & E. faecium \\
\hline
\end{tabular}

$\mathrm{S}$, susceptible (no MIC given); ${ }^{1}$ Acquisition of $\operatorname{van} A$, van $B$ or vanD genes in addition to vanC1/C2 genes - rare event; ${ }^{2}$ subtypes exist (vanB1-3, vanD1-5, vanG1-2); ${ }^{3}$ several strains exist with different teicoplanin MICs; ${ }^{4}$ data from a presentation given by R. Leclercq, ESCMID conference on Enterococci, Barcelona/ES, 18.-20.11.2009.

\section{Table 1. Types of acquired vancomycin resistance in enterococci}

Nucleotide identity varied also along the other elements of the vanC-4 cluster with genes vanX $Y_{C}$, van $T_{C}$, van $R_{C}$, and vanSc showing $88-93 \%$ identity with corresponding genes of the van C-2/-3 cluster (see below and Fig. 1). VanC type resistance is mediated via a modified DAla-D-Ser moiety similar to VanE/G/L/N types reaching also a similar low level of resistance only (Arias et al., 2000). All these resistance types require activity of a serine racemase converting L-Ser into D-Ser, the first one of these enzymes/genes was described in E. gallinarum (Arias et al., 1999). The vanC-1 gene cluster of E. gallinarum contains a ligase gene vanC-1, a combined D-Ala-D-Ala dipeptidase/carboxypeptidase vanXY $Y_{C}$ gene, a vanT racemase gene and two genes encoding a sensor kinase/response regular two-component regulatory system $v a n R_{C}$ and $v a n S_{C}$ (Reynolds et al., 1999; Reynolds and Courvalin 2005). The vanC-2 cluster in E. casseliflavus showed a composition similar to the vanC-1 cluster in E. gallinarum (Dutta and Reynolds 2002). Due to the different VanC resistance mechanism a vanH equivalent is functionally not required and missing. Initially it was thought that VanC type resistance was always constitutively expressed as a species-specific property. However, 
E. casseliflavus expressed an inducible resistance phenotype which was detected several hours after induction in vitro (Dutta and Reynolds 2002). E. gallinarum isolates expressing an inducible and constitutive phenotypes were identified; mutational changes in the amino acid sequences of the corresponding sensor histidine kinases $\mathrm{VanS}_{\mathrm{C}}$ in constitutive and inducible strains were demonstrated (Panesso et al., 2005). Acquisition of mobile vanA, vanB and vanD gene clusters additional to the natural vanC-1/-2 cluster in $E$. gallinarum/casseliflavus may lead to high-level vancomycin resistance in these strains; however, their prevalence remains low (Foglia et al., 2003; Mammina et al., 2005; Haenni et al., 2009; Neves et al., 2009).

\subsection{The VanD resistance type}

The basic organization of the vanD operons, which are located exclusively on the chromosome, is similar to that of the vanA and $\operatorname{van} B$ clusters (Casadewall and Courvalin 1999; Boyd et al., 2000; Depardieu et al., 2003b; Depardieu et al., 2004; Boyd et al., 2004). Genes equivalent to van $Z$ or vanW are absent. The vanD resistance clusters appear as a remarkable example of how by certain mutational events regulatory networks adjust and finetune gene expression: VanD-type strains have negligible Van $\mathrm{X}_{\mathrm{D}}$ activity, an enzyme that normally shuts down synthesis of vancomycin-susceptible, housekeeping call wall precursors. This otherwise physiological drawback is compensated by an inactivated D-Ala-D-Ala ligase (deletions, point mutations, insertion) host enzyme, preventing synthesis of vancomycinsusceptible precursors ending in D-Ala-D-Ala. However, vanD expression and corresponding essential cell wall precursor synthesis would still request induction by glycopeptides (vancomycin dependence). Consequently all investigated VanD type E. faecalis, E. faecium and E. avium strains show a constitutive resistance phenotype resulting from different mutations in the $\operatorname{VanS}_{\mathrm{D}}$ sensor or $\operatorname{VanR}_{\mathrm{D}}$ regulator. Another unusual feature of VanD-type strains is their only slightly diminished susceptibility to teicoplanin (Tab. 1) which cannot be explained on the basis of already known DNA sequence diversities. Due to different strategies in establishing those complex and highly regulated networks independently and via different routes five different vanD cluster types had arranged and were characterized so far (Boyd et al., 2000; Depardieu et al., 2004). Up to now, VanD-type resistance still is a rare van resistance type among enterococci but has been described in a VanC type E. gallinarum N040414, too (Boyd et al., 2006b). In this strain the vancomycin resistance phenotype is constitutive but typical VanD strain features are lacking (mutations in van $S_{D}$ linked to constitutive expression; shut-down of housekeeping D-Ala-D-Ala ligase activity, etc.). A vanD cluster was also described in E. raffinosus (Tanimoto et al., 2006). It showed almost identity to the vanD4 gene cluster of E. faecium 10/96A and expressed all features of typical VanD type resistance such as an inducible resistance phenotype based on $\mathrm{VanS}_{\mathrm{D}}$ mutations.

Different VanD-type enterococci present a number of different combinations of mutations (mainly in $V_{a n S}$ ) suggesting an independent development and convergent evolution (Depardieu et al., 2009). These various modifications also led to a wide range of resistance phenotypes with low to high-level vancomycin resistant strains (16-512 mg/L) and susceptibility $(0,5 \mathrm{mg} / \mathrm{L})$ and low to high-level resistance to teicoplanin $(\leq 64 \mathrm{mg} / \mathrm{L})$ (Tab. 1$)$. Remarkably, VanD strain E. faecium BM4656 had a wildtype Ddl enzyme being the only VanD strain with a functional D-Ala-D-Ala ligase. In this strain, also enzymes $\operatorname{Van}_{\mathrm{D}}$ and Van $Y_{D}$ were active being essentiell for shutting down synthesis of glycopeptide-susceptible 
cell wall precursors in a background of an active host Ddl enzyme for mediating vancomycin resistance (Fig. 3) (Depardieu et al., 2009).

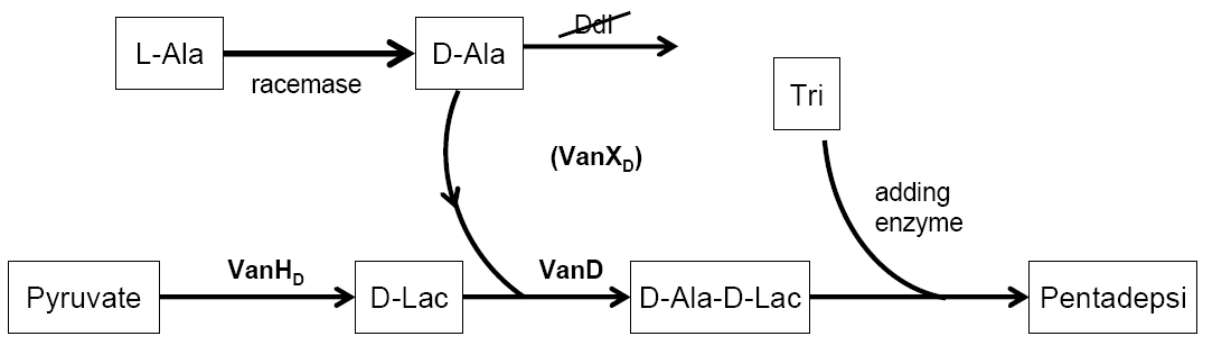

Ddl, D-alanine:D-alanine ligase; adding enzyme is a synthetase; Pentadepsi, L-Ala- $\gamma-\mathrm{D}-\mathrm{Glu}-\mathrm{L}-\mathrm{Lys}-\mathrm{D}-\mathrm{Ala}-$ D-Lac; Tri, L-Ala- $\gamma$-D-Glu-L-Lys. Tri and Pentadepsi represent amino acid side chains linked to the enterococcal peptidoglycan disaccharide precursor $\mathrm{N}$-acetyl-glucosamin- $\mathrm{N}$-acetyl-muramic acid. Resistance enzymes encoded by the vanD cluster are shown in bold. [Figure adapted from (Courvalin 2006)].

Fig. 3. VanD-type glycopeptide resistance. Synthesis of peptidoglycan precursors in a VanD-type resistant strain. Dependence on the presence of vancomycin in a background of reduced $\operatorname{Van} X_{D}$ activity $\left(\operatorname{Van} X_{D}\right)$ and a non-functional $\mathrm{Ddl}$ is compensated by mutations in $\operatorname{VanR}_{\mathrm{D}}$ or VanS $\mathrm{D}_{\mathrm{D}}$ leading to a constitutive resistance phenotype (not demonstrated in details; see also main text and Fig. 2).

\subsection{The VanE resistance type}

Isolates representing a VanE resistance type were described in a few E. faecalis strains from Northern America and Australia (Fines et al., 1999; Abadia Patino et al., 2002; Boyd et al., 2002; Abadia Patino et al., 2004). The vanE resistance cluster resembles structures of the vanC1 cluster naturally occurring in E. gallinarum (Fig. 2) and shows also highest similarities with the corresponding proteins. Therefore resistance is mediated by producing D-Ala-DSer-terminated cell wall precursors (Tab. 1). Due to that and as compared to the VanC resistance type, VanE type vancomycin resistance requires a VanT racemase converting LSer into D-Ser (Fines et al., 1999; Abadia Patino et al., 2002). VanE strains remain teicoplaninsusceptible and show moderate to low levels of inducible vancomycin resistance. Despite this phenotype, sequence determination suggested a putative non-functional VanS $S_{\mathrm{E}}$ protein indicating cross-talk between the $\operatorname{Van} R_{\mathrm{E}}$ response regulator and other functional membranelocated kinase activators. All five consecutive genes of the vanE gene cluster were cotranscribed from a single promoter (Abadia Patino et al., 2004). Downstream the vanE cluster in a single Canadian VanE-type E. faecalis an integrase gene is found, which may have been involved in the acquisition of this operon; however, when tested in vitro the vanE cluster was in all attempts not transferable (Boyd et al., 2002). Initially a van gene cluster designated vanE has been described in Paenibacillus popilliae showing 74-79\% protein sequence identity with the corresponding essential proteins $\mathrm{VanH} / \mathrm{A} / \mathrm{X}$ in vanA clusters (Patel et al., 2000; Patel 2000; Guardabassi et al., 2005; Guardabassi and Agerso 2006). This has later been renamed into vanF (see chapter 5).

\subsection{The VanG resistance type}

E. faecalis possessing a vanG cluster were low-level vancomycin-resistant and teicoplaninsusceptible (McKessar et al., 2000; Depardieu et al., 2003a; Boyd et al., 2006a). Resistance is 
mediated via inducible synthesis of D-Ala-D-Ser-terminated cell wall precursors. Only few isolates have been described and van $G$ gene clusters identified allow differentiation into two subtypes. The chromosomal van $G$ cluster consists of seven genes which according to its order and gene composition appear to be reassembled from different van operons (Fig. 1). In contrast to all the other van operons, the van $\mathrm{v}$ cluster encodes three putative gene products with regulatory functions. Besides the common $v a n \mathrm{R}_{\mathrm{G}}$ and $v a n \mathrm{~S}_{\mathrm{G}}$ determinants a van $\mathrm{U}_{\mathrm{G}}$ gene encoding an additional putative transcriptional activator was identified (Depardieu et al., 2003a; Boyd et al., 2006a). The van $Y$ gene is present but a frame-shift mutation resulting in premature termination of the encoded protein accounted for the lack of disaccharidetetrapeptide prescursors in the cytoplasm (Depardieu et al., 2003a). VanG-type resistance was successfully transferred in vitro and acquisition of the vanG cluster was associated with a transfer of a $240 \mathrm{~kb}$ chromosomal fragment flanked by imperfect inverted repeats (Depardieu et al., 2003a). Crystallisation and X-ray analysis of the VanG D-Ala-D-Ser ligase in complex with ADP was described recently (Weber et al., 2009).

\subsection{The VanL resistance type}

A single E. faecalis isolate from Canada (N06-0364) expressed low level vancomycin resistance by a new mechanism called VanL (Boyd et al., 2008). The corresponding VanL gene mediates D-Ala-D-Ser ligation. The vanL gene cluster was similar in organization to the van $C$ operon, but the VanT serine racemase was encoded by two separate genes, vanTm (membrane binding) and $\operatorname{van} r_{\mathrm{L}}$ (racemase) resembling the two functional domains of the otherwise combined vanT type racemase (Fig. 1)(Boyd et al., 2008). The putative VanL ligase exhibited 51 and $49 \%$ sequence identity to the VanE and VanC ligases, respectively. All attempts to transfer the vanL gene cluster in vitro failed. The E. faecalis isolate N06-0364 did not demonstrate plasmids assuming that the vanL gene cluster was chromosomally encoded.

\subsection{The VanM resistance type}

The vanM genotype was described in seven Chinese VRE isolates originating from a single hospital and revealing three different MLST (ST18, ST78, ST341) and five PFGE types/subtypes (Xu et al., 2010). A single VanM VRE was investigated in greater details. The translated sequence of VanM, the corresponding ligase, showed highest similarity to the VanA, the corresponding VanM gene product mediates ligation of the D-Ala-D-Lac peptide. The vanM gene cluster showed a gene arrangement similar to vanB and vanD with the $\mathrm{D}, \mathrm{D}-$ carboxypeptidase gene van $Y_{M}$ preceding the ligase gene (Fig. 1). VanM type resistance was transferable by conjugation in vitro and plasmid-located. VanM phenotype showed in vitro resistance against vancomycin and tecioplanin in six of seven isolates investigated (the single ST341 isolate was susceptible to teicoplanin).

\subsection{The vancomycin dependence phenotype}

Soon after the first appearance of vanA- and vanB-type VRE, strains with unusual resistance phenotypes were notified including constitutively resistant strains and even vancomycindependent isolates of the species E. faecalis, E. faecium and E. avium (Woodford et al., 1994; Rosato et al., 1995; Sifaoui and Gutmann 1997). Features of in vitro selected strains were similar to variants identified from clinical cases mostly associated with long term 
vancomycin treatment. In vancomycin-dependent VRE the housekeeping D-Ala-D-Ala ligase ( $d d l$ gene) is not functional due to modifications in the coding sequence (point mutations, deletions, insertions). Consequently depletion of D-Ala-D-Ala dipeptides leads to an impaired cell wall synthesis. The effect could be complemented by providing the missing D-Ala-D-Ala dipeptide (Sng et al., 1998a) or similar di- or depsipeptides. Vancomycin is capable of inducing the VanA or VanB type resistance and thus providing DAla-D-Lac as the necessary substrate for a revived cell wall synthesis. These strains remain dependent on the inducing effect of vancomycin for an ongoing cell wall synthesis. Dependence on vancomycin could be circumvented by subsequent mutations targeting the two-component regulatory system of VanR and/or VanS. Mutations in the histidine kinase or the regulator may bypass the inducing property of the antimicrobial compound in leading to a constitutive resistance phenotype not requiring vancomycin anymore. This switch from inducible to constitutive vancomycin resistance phenotype may also appear independently from a previous vancomycin dependence phenotype (Sng et al., 1998b; Baptista et al., 1999). As described recently in a VanB type VRE, a mutation in the transcription terminator of the regulatory genes resulting in transcriptional readthrough of the resistance genes from the $\mathrm{P}_{\mathrm{RB}}$ promoter in the absence of vancomycin may also circumvent vancomycin dependence and lead to a constitutive phenotype (San Millan et al., $2009 \mathrm{~b}$ ). Expression of vancomycin resistance comes along with a fitness burden under nonselective conditions (in the absence of glycopeptides). Accordingly VRE with a constitutive phenotype are less competitive under non-selective conditions (Foucault et al., 2010).

\section{The van alphabet in non-enterococcal strains}

\subsection{The van alphabet in intestinal and environmental bacteria and glycopeptide producers}

Prevalence studies revealed occurrence of different van genes like vanB, vanD and van $\mathrm{v}$ in non-enterococcal, human intestinal colonizers of Clostridium spp., Ruminococcus spp. and others (Patel 2000; Stinear et al., 2001; Domingo et al., 2005; Ballard et al., 2005b; Domingo et al., 2007). One of these isolates was investigated further and a new, naturally vancomycinresistant species, Ruminococcus gauvreauii, was identified possessing a vanD gene cluster (Domingo et al., 2008). In strains of Clostridium symbiosum an entire vanB2 type Tn1549 cluster was identified which was transferable in vitro and in vivo in the digestive tract of mice highlighting the important role that commensal, intestinal, non-enterococcal hosts may play for acquiring, preserving and distributing (vancomycin) resistance genes to nosocomial pathogens (Launay et al., 2006). The corresponding conjugative transposon Tn1549 encodes all necessary functions for a successful transfer of the element across species and genus barriers also demonstrating its potential to transfer vanB type vancomycin resistance from Enterococcus to other important nosocomial pathogens like Staphylococcus spp, C. difficile and others (Tsvetkova et al., 2010). A large number of the C. difficile genome of the multi-drug resistant, clinical strain 630 consisted of mobile, genetic elements $(11 \%)$ including a tet(M)encoding self-conjugative transposon Tn5397 (Sebaihia et al., 2006). Conjugative transposons like Tn5397/Tn916 (and also Tn1549) are easily exchanged between members of different bacterial species and genera and are identified in a wide range of different, Gram-positive bacterial species capable of self-transfer and mobilisation of other, genetic elements (Roberts et al., 2001; Jasni et al., 2010; Roberts and Mullany 2011). C. difficile 630 also contained an 
element with similarity to a vanG type cluster; however, neither this cluster was complete nor was the strain vancomycin-resistant (Sebaihia et al., 2006). Clostridium innocuum is naturally intermediate-resistant to vancomycin (MIC $=8 \mathrm{mg} / \mathrm{L}$ ). The mechanism of resistance was investigated in strain NCIB 10674 and found to be related due to the activity of two chromosomally encoded Ddl ligases and a racemase allowing the synthesis of a peptidoglycan precursor terminating in D-Ser similar to VanC/E/G/L type vancomycin resistance (David et al., 2004).

Certain vancomycin-resistant strains of fecal streptococci belonging to the Streptococcus bovis group (e.g., S. gallolyticus, S. lutetiensis) were found to contain vanA and vanB genes (Poyart et al., 1997; Mevius et al., 1998); however, these strains were not investigated in greater molecular details. Results of another study revealed that the entire vanB2 type Tn5397 conjugative transposon from a S. lutetiensis donor was capable to transfer into E. faecium and E. faecalis recipients in a recA-independent manner (Dahl and Sundsfjord 2003).

Strains of Paenibacillus popilliae and Rhodococcus spp. contain vanA/B-like resistance gene clusters originally called vanE in P. popilliae and later on designated vanF (Patel et al., 2000; Guardabassi et al., 2004; Guardabassi et al., 2005; Guardabassi and Agerso 2006). P. popilliae ATCC 14706 is high-level vancomycin-resistant and contained a gene cluster with $\operatorname{van} Y_{F}$ and van $Z_{F}$ preceding the vanHFX co-transcribed gene cluster. Two genes encoding a twocomponent regulatory system of the VanRS type were identified ca. $3 \mathrm{~kb}$ upstream van $Y_{F}$ associated with an inducible VanF phenotype (Fraimow et al., 2005).

A number of Lactobacillus, Pediococcus, Leuconostoc and Lactococcus species are naturally resistant to vancomycin. This is an intrinsic property of certain species and, as known so far, mainly linked to a modified cell wall synthesis mediated via alternative precursors, functionally similar but not linked to an acquisition of any van gene cluster (Goffin et al., 2005). For instance, in Leuconostoc mesenteroides a Ddl enzyme with a residual D-Ala-D-Lac activity was identified allowing the production of vancomycin-resistant cell wall precursors (Kuzin et al., 2000). In Lactobacillus plantarum vancomycin resistance is also mediated via a species-specific Ddl ligase capable of synthesising D-Ala-D-Lac depsipeptides and, in addition, an intrinsic VanX-like D-Ala-D-Ala dipeptidase destroying vancomycinsusceptible cell wall precursors (Deghorain et al., 2007).

Certain soil bacteria produce glycopeptide antibiotics including vancomycin (Amycolatopsis orientalis) and teicoplanin (Actinoplanes teichomyceticus) as secondary metabolites. They prevent themselves from sensitivity against their own products by intrinsic resistance mechanisms similar but not identical to acquired resistance types in Enterococcus spp. (Marshall et al., 1997; Marshall et al., 1998; Patel 2000). It was speculated that enterococcal resistance genes originated from corresponding glycopeptide producers (Marshall et al., 1998; Patel 2000); however, comparably weak amino acid and nucleotide similarities among key genes and proteins involved in the resistance mechanism and the comparably high \% GC of the VanRS regulatory system in the glycopeptide producers Streptomyces toyocaensis and $A$. orientalis suggested that a possible exchange between glycopeptide producers and nosocomial pathogens having acquired resistance properties did not happen recently (Courvalin 2005).

The anaerobic, Gram-positive, dehalogenating bacterium Desulfitobacterium hafniense Y51 was vancomycin-resistant by an inducible resistance phenotype (Patel et al., 2000). The 
strain contained a resistance Ddl enzyme with a preferred D-Ala-D-Lac ligase activity and a vancomycin resistance gene cluster showing a slightly different gene arrangement as compared with van $A / B$ clusters. The essential van $H$ homologue was missing in this cluster element; however, genome analysis of $D$. hafniense Y51 revealed at least four D-isomerspecific 2-hydroxyacid dehydrogenase genes capable in situ to perform the relevant vanHtype reaction. Nevertheless, the physiological role, the overall prevalence of this gene cluster and the phylogenetic relation to acquired resistance gene clusters in Enterococcus spp. remain unclear so far (Patel 2000).

It is known that intestinal colonisation could precede subsequent infections with VRE (Donskey 2004). Screening patients at risk for a colonisation with VRE is an important indicator in preventing and controlling VRE infections and outbreaks (Zirakzadeh and Patel 2006). Molecular assays provide certain advantages over microbiological tests in terms of time, sensitivity and accuracy. Prevalence of van genes, especially vanB in intestinal, nonenterococcal species impairs performance of rapid, molecular screening assays targeting the corresponding resistance genes only (Stamper et al., 2007; Mak et al., 2009; Usacheva et al., 2010). Results of a number of studies performed with various commercially available diagnostic assays in Northern America, Australia, Asia and different countries in Europe also revealed that $\operatorname{vanB}$ is generally prevalent among human intestinal colonizers and that this is not a specific property of human intestinal colonisers in certain parts of the world (Ballard et al., 2005a; Stamper et al., 2007; Mak et al., 2009; Usacheva et al., 2010; Lee et al., 2010; Marner et al., 2011; Werner et al., 2011c).

\subsection{The vanA gene cluster in Staphylococcus aureus}

Vancomycin is the antibiotic of choice for treating MRSA infected patients. Insusceptibility to vancomycin associated with treatment failure is insofar a matter of serious concern. Various microbiological changes could lead to reduced susceptibility against vancomycin including increased cell wall thickness, activated cell wall synthesis and reduced autolysis. The former changes are based on a modified host gene expression of determinants involved in cell wall synthesis leading to a so-called "trapping effect" where more unlinked cell wall precursors are present being able to bind (more) vancomycin ("to trap" the drug)(Cui et al., 2005; Werner et al., 2008c; Nannini et al., 2010). The Vancomycin intermediate-resistant phenotype (VISA) could be expressed homogeneously or only in a subset of investigated strains $\left(1\right.$ of $10^{5}$ cells $=$ heterogeneous VISA - hVISA), the latter requires a sophisticated diagnostics via a population-based-analysis profiling (PAP)(Howden et al., 2010). VISA or hVISA phenotypes are not associated with (van) gene acquisition.

Early in vitro studies demonstrated the capability of a transfer of the enterococcal VanA type resistance into $S$. aureus/MRSA rendering descendents as vancomycin- and oxacillinresistant (Noble et al., 1992). The first clinical vanA-mediated high-level vancomycinresistant MRSA (VRSA) was isolated from a dialysis patient in Michigan, USA (Weigel et al., 2003; Chang et al., 2003). Since then, less than a dozen additional cases have been described, nine in the United States (Michigan [n=7], New York and Pennsylvania) and each one in India and in Iran (the latter two were not confirmed elsewhere) (Sievert et al., 2008; Finks et al., 2009; Nannini et al., 2010).

The US VRSA isolates showed high-level vancomycin resistance of $>32 \mathrm{mg} / \mathrm{L}$. All US patients affected by VRSA infections had a history of several underlying conditions and 
accordingly, all of them were treated extensively with antibiotics including vancomycin and most of them were co-colonized with VRE, respectively. The US VRSA isolates exhibited the SmaI macrorestriction patterns USA100, SCCmecII and USA800, SCCmecIV and all isolates could be assigned to sequence type 5 by multilocus sequence typing (MLST). Typing of corresponding strains, their resistance plasmids and corresponding Tn1546-like vanA clusters revealed that the isolates were unique and had evolved separately (see next paragraph).

From the first case patient a MRSA strain, a vanA-type E. faecalis and a vanA-type MRSA were isolated which allowed constructing a scenario where the MRSA received the vanA type resistance from the resistant co-colonising $E$. faecalis. This has been confirmed by molecular analysis of the corresponding vanA-type plasmids from related VRSA and MRSA isolates (Weigel et al., 2003; Clark et al., 2005; Zhu et al., 2008). The VRSA isolate contained a $58 \mathrm{~kb}$ conjugative plasmid pLW1043, the MRSA a ca. $47 \mathrm{~kb}$ pAM829 plasmid and the VRE two plasmids of 45 and $95 \mathrm{~kb}$. Restriction digestion revealed similar patterns for the pLW1043 and pAM829 plasmids but not for the E. faecalis plasmids (Weigel et al., 2003). pLW1043 was fully sequenced and revealed a Tn1546-like vanA cluster integrated between the blaZ (beta-lactamase) and the aacA-aphD (gentamicin resistance) regions. It showed a mosaic-like structure, but the backbone was similar to staphylococcal type pSK41 plasmids and different from typical enterococcal plasmids suggesting acquisition of the vanA cluster by a resident staphylococcal-type plasmid (Kwong et al., 2008; Weaver et al., 2009). Interestingly, majority of other VRSA and co-colonising VRE isolates contained inc18-type vanA plasmids investigated in a follow up study (Zhu et al., 2008). The inc18-type plasmids represent broad-host range plasmids widely prevalent among Gram-positive bacteria of different enterococcal, staphylococcal and streptococcal species (Weaver et al., 2009). Plasmids from three VRSA cases were sequenced [plasmids pWZ7140 (47,277 bp), pWZ909 (42,602 bp), and pWZ1668 (48,365 bp)]. They were almost identical among each other and to a corresponding vanA plasmid from co-colonising E. faecalis strains revealing a possible direct transfer from an E. faecalis donor into MRSA (Zhu et al., 2008). Molecular studies with isogenic MRSA and VRSA isolates revealed that acquired VanA-type resistance was highly costly to the host, when induced (Foucault et al., 2009). In the absence of induction, the determined biological cost was minimal suggesting a serious potential for the dissemination of VRSA clinical isolates.

An comparison of US VRSA isolates (Michigan VRSA, Pennsylvania VRSA) to the vanAtype $E$. faecalis from the index patient, the possible donor of the resistance gene cluster for the Michigan VRSA, revealed interesting details on the resistance gene regulation and expression in different hosts (Perichon and Courvalin 2004). The Michigan VRSA was highly resistant to both glycopeptides, whereas the Pennsylvania VRSA displayed low-level resistance to vancomycin and reduced susceptibility to teicoplanin. Resistance genes were expressed at similarly high levels in the two VRSA and the vanA-type E. faecalis; however, resistance expression was notably delayed in the Pennsylvania strain. Resistance was lost at non-selective condition from the Pennsylvania VRSA. In contrast, it was stable in the Michigan VRSA and the VRE (Perichon and Courvalin 2004). Two Michigan VRSA isolates, designated VRSA-7 and VRSA-9 showed a vancomycin dependence phenotype. Molecular studies revealed a similar mechanism as known from enterococci with the corresponding resistance phenotype. VRSA-7 and VRSA-9 contained different mutations in the housekeeping D-Ala-D-Ala ligase leading to a decreased activity and dependence on the 
vanA-type D-Ala-D-Lac ligase for an ongoing cell wall synthesis (Moubareck et al., 2009; Meziane-Cherif et al., 2010). Strikingly, peptidoglycan precursors ending in D-Ala-D-Lac are not processed by PBP2a, the oxacillin-resistant penicillin binding protein encoded by mec $A$ and consequently the VRSA-7 and VRSA-9 were fully susceptible to oxacillin, despite the production of a wild-type PBP2a (Moubareck et al., 2009). This also means that the combination of a beta-lactam and a glycopeptide antibiotic shows a synergistic effect for VRSA in general (Perichon and Courvalin 2006). Comparison of the two vancomycindependent VRSA isolates (VRSA-7/-9) indicated that the levels of vancomycin dependence and susceptibility to $\beta$-lactams correlate with the degree of D-Ala-D-Ala ligase impairment (Meziane-Cherif et al., 2010).

\section{Prevalence of VRE among the hospital setting}

Modern molecular typing techniques (AFLP, MLVA, MLST)2 allow differentiating between commensal and hospital-associated/outbreak E. faecium isolates including vancomycinresistant and vancomycin-susceptible variants (Willems and Bonten 2007; Willems and van Schaik W. 2009). Genomic diversity is higher in commensal E. faecium isolates (animal/human) as compared to hospital strains types that especially show a predominance of a number of specific MLST or MLVA types (Werner et al., 2007b; Werner et al., 2011a). Results of a comparative genome-based study revealed a distinct composition of the accessory genome in hospital-associated E. faecium strains (Leavis et al., 2007). Results have been confirmed by recent comparative analyses of completely sequenced $E$. faecium genomes (van Schaik et al., 2010; Palmer et al., 2010). The current model predicts that spread of ampicillin-resistant, hospital-associated E. faecium strains is a pre-requisite for successful establishment of VRE and further dissemination of vancomycin resistance among the hospital E. faecium population in general (Willems and Bonten 2007; Galloway-Pena et al., 2009; Willems and van Schaik W. 2009). To a larger or lesser extent, non-microbiological factors such as antibiotic consumption (particular classes and in general); "colonisation pressure", "understaffing", compliance with hand hygiene and other infection control measures also affect the role and number of enterococcal infections (Bonten et al., 1998; Cetinkaya et al., 2000; Murray 2000; Bonten et al., 2001; Panesso et al., 2010). Therefore, it might not come as a big surprise that despite having similar starting points and preconditions different countries experienced diverse trends in VRE prevalence. Already during the early and mid-1990s, epidemic clonal types of E. faecium were prevalent in hospitals in many countries, and this coincided in some European countries with a high prevalence of vancomycin resistance among E. faecium from animals and healthy volunteers linked to a widespread use of avoparcin as a growth promoter in commercial animal husbandry (Murray 1990; Murray 2000; Bonten et al., 2001; Panesso et al., 2010). However, VRE rates in clinical isolates increased in many countries and peaked only almost ten years later when glycopeptide resistance had already declined in the non-hospital reservoir. Retrospective epidemiological analyses in hospitals experiencing larger VRE outbreaks revealed that changes in specific procedures such as antibiotic policy, staffing, infection prevention and control regimes were, in some instances, significantly associated with increasing VRE rates, whereas in other settings this could not be shown. Increased VRE

\footnotetext{
${ }^{2}$ AFLP, Amplified-fragment length polymorphism; MLVA, Multiple Locus Variable number of tandem repeat Analysis; MLST, Multi-Locus Sequence Typing
} 
prevalence is partly associated with spread of single, distinct epidemic clones or types (Klare et al., 2005; Top et al., 2007; Bonora et al., 2007; Werner et al., 2007c; Valdezate et al., 2009; Zhu et al., 2010; Johnson et al., 2010; Hsieh et al., 2010). In contrast, VRE outbreaks in single centres tend to be polyclonal suggesting a diverse population of hospital-acquired $E$. faecium strains and a highly mobile resistance determinant capable of spreading widely among suitable recipient strains (Yoo et al., 2006; Deplano et al., 2007; Kawalec et al., 2007; Borgmann et al., 2007; Werner et al., 2007c; Hsieh et al., 2009). Many facets of VRE and vancomycin resistance epidemiology are currently not fully understood and the question why vancomycin resistance is still mainly limited to $E$. faecium remains mainly unanswered (Garcia-Migura et al., 2007; Garcia-Migura et al., 2008; Werner et al., 2010b).

The main prevalent genotypes of acquired vancomycin resistance in enterococci worldwide are $v a n A$ and to a lesser extent $v a n B$. The reservoir for van $A / B$ gene clusters is mainly in $E$. faecium; van $A / B$-type resistant $E$. faecalis remain rare all over the world. Countries experiencing problems with increasing or significant higher rates of VRE always report about vancomycin-resistant E. faecium. Infections with members of other enterococcal species remain rare although also outbreaks with vanA/B-type resistant E. faecalis, E. raffinosus or VanC-type E. gallinarum were reported (Foglia et al., 2003; Kawalec et al., 2007; Neves et al., 2009; Shirano et al., 2010). In conclusion, the problem of VRE is mainly an issue of vanA-type vancomycin-resistant E. faecium (see the following).

\subsection{Europe}

Several national and European surveillance systems collect data on vancomycin resistance in enterococci. In some countries mandatory VRE surveillance is already established, in others coverage for the general population or selected settings is rather limited and the available data do not allow reliable statistical analyses and in some countries data are completely lacking. The most successful European antibiotic resistance surveillance scheme is the European Antimicrobial Resistance Surveillance System/network (EARSS/EARSNet), ${ }^{3}$ which was established in 1998 and is now funded by the European Centre for Disease Prevention and Control ECDC. EARS-Net collects data on antibiotic resistances in indicator bacteria exclusively from invasive (bloodstream) infections currently covering Streptococcus pneumoniae, S. aureus, Escherichia coli, E. faecalis/E. faecium, Klebsiella pneumoniae and Pseudomonas aeruginosa. In 2008 over 900 microbiological laboratories serving more than 1,500 hospitals from 33 countries provided susceptibility data from more than 700,000 invasive isolates. Inter-country comparison of collected data in the given setting reveals some drawbacks and limitations (not discussed here, see EARS reports and website). Accordingly, simple comparisons of surveillance data over time and between countries or even within single countries should be done carefully (see also chapter 4 in the EARS Annual Report 2008)(EARSS 2009). VRE surveillance within Europe has recently been reviewed and the reader is referred to this paper for any further details (Werner et al., 2008a). In the following only a short summary and, in addition, some new aspects to these previous reports are given.

\footnotetext{
${ }^{3} \mathrm{http}: / /$ ecdc.europa.eu/en/activities/surveillance/EARS-Net/about_EARS-Net/Pages/about_networ k.aspx
} 
VRE surveillance in the Nordic European countries, Norway, Denmark, Sweden, Finland and Iceland, is based on national public health programmes for containment of antimicrobial resistance, participation in EARS and in some countries case notification from laboratories and clinicians. The Nordic countries have traditionally had a low prevalence of antimicrobial resistance, and this is also true for VRE. Within the last years a recognisable reservoir of vancomycin resistance among animal enterococci was demonstrated despite the ban of using any antimicrobial growth promoter, especially avoparcin (Sorum et al., 2006; Nilsson et al., 2009a; Nilsson et al., 2009b). It is still unclear if and to what extent this reservoir influences the situation in the clinical setting. In Sweden, the situation has been stable with 18-53 cases of VRE infections and colonisations being reported annually between 2000 and 2007. However, the situation has changed rapidly with the predominant spread of a vanB E. faecium clone with 634 among 760 VRE cases described within a 20 months' period from 2007-2009 (Soderblom et al., 2010). General prevalence of VRE in a Swedish hospital during a post-outbreak situation was still low (Fang et al., 2010).

There is no single comprehensive surveillance scheme for monitoring VRE infections in the United Kingdom (UK). However, bacteraemia caused by VRE is monitored by four complementary surveillance programmes, with varying degrees of coverage and participation (Werner et al., 2008a). Numbers of VRE cases from invasive infections and general prevalence of vancomycin resistance in enterococci from the clinical setting is comparably high in relation to other European countries. Given the tremendous activities and partial success in reducing the MRSA burden in UK hospitals one might expect that these measures also lead to a reduction of VRE bacteraemia cases. Rates of vancomycin resistance among invasive E. faecium isolates varied between 33\% (2005), 18\% (2006), $21 \%$ (2007), 28\% (2008), 13\% (2009) (data from EARS-Net). The Department of Health mandatory glycopeptide-resistant enterococcal bacteraemia reporting scheme collects the total number of VRE bacteraemias in England each year. A supposed reduction in bacteraemia cases in both surveillance schemes conflicts with a possible reporting bias of participating hospitals and laboratories and it has to be shown that the supposed trends will be stable for the coming years ${ }^{4}$. The British Society for Antimicrobial Chemotherapy (BSAC) Bacteraemia Surveillance Programme reports data until 2008; however, a specific trend cannot be specified for "E. faecium" and "vancomycin resistance"5.

Certain European countries (Netherlands, Denmark, Spain) showed a wide prevalence of hospital-associated clonal types of E. faecium but vancomycin resistance rates are still low (Oteo et al., 2007; Lester et al., 2008; Top et al., 2008b; Valdezate et al., 2009; Lester et al., 2009). In other countries rates of VRE remain at a comparably high rate such as Ireland and Portugal $^{5}$ (Novais et al., 2008; Morris-Downes et al., 2010). Decreasing rates were considered significant in countries like Italy, France, Israel and Greece; however, it has to be documented if these trends are indeed lasting and not biased by other, so far unknown factors (see EARS-Net data).

\footnotetext{
${ }^{4}$ http://www.hpa.org.uk/web/HPAwebFile/HPAweb_C/GGTSPU-vaccine-see.rki.de-11200-6823805DAT/1278944284940

5 http://www.bsacsurv.org/mrsweb/bacteraemia?organism=E. \%20faecium\&antimicrobial=van\&year= All\&country $=$ All\&summary $=$ Enzyme $\% 20$ Production\&formname $=$ bsac_bacteraemia\&submit $=$ Search $\% 2$ $0 \% 28 \% 20$ this $\% 20$ tab $\% 20 \% 29$
} 
Molecular typing of clinical enterococci sent to the German Focal Laboratory for Enterococcus revealed a significant increase in the number of vanB-type E. faecium among vancomycin-resistant E. faecium prevalent in different German hospitals (2006: 53/302, 18\%; 2007: 65/249, 26\%; 2008: 95/298, 32\%; 2009: 157/333, 52\%; (Klare et al., 2010)). Preliminary findings direct to a similar trend in other European countries like Sweden (Soderblom et al., 2010; Fang et al., 2010). If this increased VanB-type prevalence is linked to a supposed reservoir of vanB among enterococcal or non-enterococcal intestinal colonizers (Stamper et al., 2007; Young et al., 2007; Graham et al., 2008; Usacheva et al., 2010; Bourdon et al., 2010; Werner et al., 2011c) or simply linked to an improved and better identification of low-level expressed VanB-type resistance (Pendle et al., 2008; Grabsch et al., 2008a; Grabsch et al., 2008b; Stamper et al., 2010) in relation to a reduced breakpoint as defined by EUCAST (EUCAST Clinical Breakpoint Table v. 1.1 2010-04-27) ${ }^{6}$ remains to be elucidated in further studies.

\subsection{Northern America}

Canada and the USA illustrate two divergent scenarios concerning vancomycin resistance rates among enterococci. In Canada resistance rates are persistently low (Karlowsky et al., 1999; Zhanel et al., 2000; Nichol et al., 2006; Zhanel et al., 2008a; Zhanel et al., 2010b). Results of a recent CANWARD study performed in 2008 among 10 participating Canadian hospitals revealed 3.1\% VRE among 320 clinical enterococcal isolates (Zhanel et al., 2010b). All 10 VRE were vanA-type E. faecium. VRE prevalence among Canadian ICU patients is low as well; VRE accounted for $<1 \%(n=17 / 4133)$ of all isolates and $6.7 \%(n=17 / 255)$ of enterococcal isolates, majority of them (88\%) possessed vanA (Zhanel et al., 2008b). Despite the low prevalence of the more common vancomycin resistance genotypes, a number of new and still rare vancomycin resistance genotypes of the vanD, vanE, van $G$ and vanL classes were identified in Canadian enterococci (Boyd et al., 2000; Van Caeseele et al., 2001; Boyd et al., 2002; Boyd et al., 2004; Boyd et al., 2006a; Boyd et al., 2008).

In contrast to the situation in Canada, vancomycin resistance among clinical enterococci from US medical centres is highly prevalent. It is mainly encoded by vanA-type resistance widely prevalent among hospital-associated clonal types of E. faecium (Karlowsky et al., 2004; Nichol et al., 2006). The rapid increase in vancomycin resistance among the E. faecium population in US hospitals in general and the intensive care setting especially after its first appearance within a 10 years' time span is a dramatic example of a fast growing resistance problem that nowadays neither can be controlled nor prevented or reversed. The obvious coincidence of a number of unfortunate circumstances and factors from either side, the health care setting (e. g., delayed compliance with infection control and prevention strategies; permission of oral vancomycin use) and the bacteria themselves (e. g., rapid spread of hospital-associated epidemic clones; vancomycin resistance genes in a stable and transferable genetic background) may have led to such a scenario (Martone 1998; Nichol et al., 2006). The Surveillance Network (TSN) collects data on blood culture isolates from patients from 268 US hospitals. Data for 2002 revealed in $67 \%$ vancomycin resistance among altogether 1.285 E. faecium isolates whereas the same resistance characteristics still remained

${ }^{6}$ http://www.eucast.org/fileadmin/src/media/PDFs/EUCAST_files/Disk_test_documents/EUCAST_b reakpoints_v1.1.pdf 
rare with $<5 \%$ among E. faecalis isolates (Karlowsky et al., 2004). Results of other studies revealed similar rates (Nichol et al., 2006; Deshpande et al., 2007). The overall situation is even impaired during the last years showing a rise in the total number of hospitalisations due to VRE infections (Ramsey and Zilberberg 2009). The Nationwide Inpatient Sample available through the Healthcare Costs and Utilization Project Website showed increased incidence of VRE infections from 3.2 to 6.5 between 2003 and 2006. An increased use of vancomycin to treat increasing numbers of MRSA and Clostridium difficile infections was one of the major drivers.

\subsection{Latin America}

In Latin America, prevalence of VRE is generally considered to be low with rates $<5 \%$ among enterococci in general and before 2005 (Quinones Perez 2006); however, reliable data based on comprehensive studies or data sets were missing. Results of a recent SENTRY study revealed a recognizable change of vancomycin resistance rates among clinical enterococcal isolates from participating Latin American countries/hospitals increasing from 5 to $15.5 \%$ within 6 years (between 2003 and 2008). The most significant increase was demonstrated for Brazil with VRE rates rising from 7 to 31\% (Sader et al., 2009). Considering that the majority of enterococcal isolates is E. faecalis which mainly remained susceptible to vancomycin, the increase of vancomycin resistance among E. faecium isolates seems even more dramatic based on the numbers specified. A molecular characterization of prospectively collected 732 enterococcal isolates from 2006 to 2008 from 32 hospitals in Colombia, Ecuador, Peru and Venezuela revealed vancomycin resistance in $6 \%$ of all isolates (Panesso et al., 2010). Considering only isolates of E. faecium $(n=111)$ prevalence of vancomycin resistance ranged from 24 to $48 \%$; however, sample size per country was quite limited and a sampling bias cannot be excluded. Nevertheless, all vancomycin-resistant $E$. faecium were of the vanA genotype and represented hospital-associated strain types as determined by MLST (ST17, ST18, ST203, ST280 and others). Tn5382-vanB2 encoded VanB type resistance was demonstrated to be linked to two epidemic clones; a ST201 E. faecalis and a ST64 E. faecium disseminated among 9 and 15 Chilean hospitals, respectively (Lopez et al., 2009).

\subsection{Asia, Australia and New Zealand}

VanB-type resistance is only highly prevalent in certain parts of the world, for instance, in Australia (Christiansen et al., 2004; Pearman 2006; Worth et al., 2008; Pendle et al., 2008; Johnson et al., 2010) or Singapore (Koh et al., 2006; Koh et al., 2009) where vanB-type vancomycin resistance among clinical $E$. faecium is more prevalent than the vanA-type. The reason(s) for this remain unknown and are not linked to a supposed larger reservoir of the vanB cluster in commensal intestinal colonizers (Padiglione et al., 2000), rates of which were similar in Australian, US-American and European studies (Stamper et al., 2007; Graham et al., 2008; Grabsch et al., 2008b; Bourdon et al., 2010; Werner et al., 2011c). A larger reservoir of vanB-type resistance in isolates from commercial animal farming associated with an avoparcin use is unlikely; avoparcin use was ceased in Australia in 2000 and Singapore has no significant agriculture at all thus excluding a distinct animal vanB-type VRE reservoir (see chapter 7). However, community carriage linked to a consumption of imported and contaminated food cannot be excluded. Studies performed in New Zealand described a 
supposed dissemination of vanA-type resistance among E. faecalis strains rather then E. faecium in a background of generally low level of vancomycin resistance (Manson et al., 2003a; Manson et al., 2003b). VRE epidemiology in other Australasian countries reflects a similar scenario as in Europe or Northern America with vanA-type resistance highly prevalent among E. faecium. Several studies performed during outbreaks in Taiwanese hospitals revealed a preferred prevalence of (hospital-associated) vanA-type vancomycinresistant E. faecium strains (Hsieh et al., 2009; Hsieh et al., 2010). In South-Korean hospitals (and outside hospitals) vanA-genotype (VanB phenotype) E. faecium were widely prevalent (Ko et al., 2005; Shin et al., 2006; Park et al., 2008). Recent reports from China revealed also a preferred prevalence of vanA-type vancomycin resistance among clinical VRE (Zheng et al., 2007a; Zheng et al., 2007b; Zhu et al., 2009).

\section{Vancomycin resistance among enterococci from farm animals, feedstuff and non-hospitalized humans and the environment}

Surveillance of antimicrobial resistance among enterococci as commensal colonizers of foodproducing animals became prominent during the early and mid 1990ies. At this time scientific and public awareness arose due to the argument that use of antimicrobial growth promoters, focused on the glycopeptide avoparcin, added to the feed of food animals in subinhibitory concentrations is capable of selecting antibiotic-resistant bacteria; here glycopeptide/vancomycin-resistant enterococci. Large studies were initiated when higher numbers of VRE were suspiciously found in environmental samples without any known reservoir in or link to use of glycopeptides in human medicine (Klare et al., 1993; Torres et al., 1994). Soon after, avoparcin, another glycopeptide class antibiotic used in animal husbandry as a feed additive (growth promoter) was identified to select VRE in the animal setting (Bates et al., 1994; Klare et al., 1995a; Klare et al., 1995b; Bates 1997). Consequently, meat samples from commercially raised animals were highly contaminated with VRE including samples of pork, beef, chicken and turkey (Klare et al., 1995a; Klare et al., 1995b; Schouten et al., 1997; Klein et al., 1998; Simonsen et al., 1998; Kruse et al., 1999). Samples from organic or private farms of smaller sizes that did not use avoparcin or feed additives at all were free of VRE (Klare et al., 1995b; Klare and Witte 1998). Following the food chain, VRE reached humans and were capable of colonizing the intestines of healthy people; in contrast, a small study in vegetarians showed no detectable VRE counts (Schouten et al., 1997; Van Den Bogaard et al., 1997; Stobberingh et al., 1999). Similar studies were performed all over Europe and data have already been reviewed in previous papers and book chapters and are thus not discussed in greater details here (Woodford et al., 1998; Klare and Witte 1998; Aarestrup et al., 2000b; Bonten et al., 2001; Klare et al., 2003). In countries within the EU, avoparcin was abandoned in Norway and Denmark in 1995, Germany 1996 and in the remaining EU countries in 1997. Studies performed in some European countries soon after identified a reduced prevalence of VRE, their numbers dropped qualitatively and quantitatively in samples from commercial animal farms, food samples and following the food chain in humans of the general population (Klare et al., 1999). However, studies from Denmark and Norway showed that other antimicrobial growth promoters may lead to a coselection phenomenon and reduced VRE numbers were only documentable when other growth promoters like macrolides (spiramycin, tylosin) were also banned. The reason was a genetic linkage of both resistance determinants erm(B) and vanA on similar plasmids (Aarestrup 2000; Borgen et al., 2002). Based on the precautionary principle the European 
Commission postponed the further use of four antimicrobial growth promoters with a supposed link (same antibiotic class) to antibiotics used in human medicine in 1998. This decision was confirmed in 2003 specifying the phasing out of all antimicrobial growth promoters within the EU [Regulation (EC) No. 1831/2003 on additives for use in animal nutrition]. However, VRE counts did not drop to zero. Studies in animal farms performed several years after the ban of several growth promoters including avoparcin revealed a permanent reservoir of VRE (Borgen et al., 2000; Borgen et al., 2001; Ghidan et al., 2008). Recent studies performed in Swedish animal farms still highlighted a considerable reservoir of VRE (Nilsson et al., 2009b). Sweden banned avoparcin and other growth promoters already in 1986 and VRE prevalence among the clinical setting as well as the general population was and still is very low but somehow widely found in sewage (Sahlstrom et al., 2009). Phenotypic and genotypic characterization of the sewage VRE identified for the majority of them (a) species E. faecium and (b) the vanB-type. PFGE analysis revealed different strains prevalent over the study period. This finding is especially noticeable since a few years later rates of VanB-type E. faecium increased in certain Swedish hospitals (Soderblom et al., 2010; Fang et al., 2010).

Outside Europe similar scenarios of VRE epidemiology were described. In Korea, VRE were still prevalent in livestock samples four years after banning avoparcin (Lim et al., 2006). VRE were isolated from $17 \%$ of the chicken samples $(n=57$ strains from 342 meat samples) and $2 \%$ of the pig samples (4 from 214 fecal samples) whereas no VRE were isolated from 110 bovine samples. All the 61 VRE isolates were vanA-type E. faecium. A study performed in Japan three years after the ban of avoparcin (1997) did not identify any VRE among 515 fresh faecal samples from 178 beef cattle, 179 pig and 158 broiler chicken farms representing all 47 Japanese prefectures (Kojima et al., 2010) whereas in 1996, one year before the ban, 3\% $(8 / 263)$ of enterococci tested were vancomycin-resistant (Yoshimura et al., 1998). However, in these two studies it was only screened for enterococci in general and subsequently resistances were determined. So it cannot be ruled out that samples contained VRE but at lower numbers then statistically recognizable with the described non-selective screening strategy. Avoparcin use was banned in Taiwan in 2000. A nationwide surveillance was initiated to study VRE prevalence on chicken farms from 2000 to 2003 (Lauderdale et al., 2007). VRE were still identified, but counts dropped in a quantitative manner, only $8.8 \%$ ( $n=$ $7 / 80$ ) of the chicken farms surveyed harboured VRE in 2003 compared with $25 \%(15 / 60)$ in 2000. Interestingly, majority were vancomycin-resistant $E$. faecalis (see below). This reflects a somehow different VRE epidemiology than in the rest of the world; similar to Australia where vanB-type E. faecium and vanA-type E. faecalis predominate (Worth et al., 2008; Johnson et al., 2010). In Australia, the general scenario appears to be different; a larger reservoir of VRE outside the clinical setting could not be identified despite an ongoing high use of avoparcin. For instance, prevalence rates of VRE in the general population were extremely low $(0,2 \%)$, the two identified VRE among 1085 community specimens were vanBtype E. faecium (Padiglione et al., 2000).

In the US, avoparcin has never been used as a feed additive, a reservoir for VRE outside the clinical setting could not be identified when screening samples from various animal farms, meat, environmental sources and stool samples from healthy people during this time (Coque et al., 1996; McDonald et al., 1997; Martone 1998). However, situation changed the last years and vancomycin resistance was prevalent among 6 of 55 pig samples investigated in 2008 (Donabedian et al., 2010). 


\section{Localization and spread of vanA- and vanB-type resistance}

Vancomycin resistance in animal, human commensal and environmental sources is mostly encoded by vanA-type resistance clusters and its reservoir is in isolates of E. faecium; thus it reflects the same situation as in the clinical setting in most parts of the world. Exchange of resistant strains among different ecosystems is less probable due to the supposed ecovar association, especially among hospital-associated E. faecium strains (see chapter 5), although dissemination across host barriers of vancomycin- and multi-resistant enterococci was described anecdotally, especially for the less strongly host-adapted E. faecalis strains (Manson et al., 2003a; Manson et al., 2003b; Manson et al., 2004; Agerso et al., 2008; Larsen et al., 2010; Hammerum et al., 2010; Freitas et al., 2011a). Vancomycin resistance among enterococci most probably spreads via a dissemination of mobile genetic elements of variants of the vanA-type element Tn1546 mostly located on mobilizable or conjugative plasmids (Sletvold et al., 2007; Novais et al., 2008; Sletvold et al., 2008; Freitas et al., 2009; Rosvoll et al., 2009; Sletvold et al., 2010; Laverde Gomez et al., 2011; Werner et al., 2011b; Freitas et al., 2011b). In vitro transfer of vanA plasmids has been determined in a number of studies (Werner et al., 1997; van den Braak et al., 1998; Werner et al., 2010b) and transfer in vivo in digestive tracts of animals and human volunteers was also shown (Moubareck et al., 2003; Lester et al., 2006; Lester and Hammerum 2010). Transfer rates under natural conditions may be higher than determined in vitro (Dahl et al., 2007).

Molecular studies revealed a tremendous number of deletions, insertions, and modifications of the original Tn1546-like structure in different not epidemiologically linked VRE leading to a wide diversity of various Tn1546 subtypes (van den Braak et al., 1998; Willems et al., 1999; Huh et al., 2004; Werner et al., 2006; Lim et al., 2006; Yoo et al., 2006). Despite its high diversity, identical cluster types were identified among clinical human and animal commensal and environmental strains suggesting a common reservoir and exchange of its mobile elements via conjugative plasmids or as part of larger mobile genomic islands in European, Asian and Australian studies (van den Braak et al., 1998; Jensen et al., 1998; Willems et al., 1999; Werner et al., 2006; Jung et al., 2007). Garcia-Migura and co-workers identified a hot spot for integration of Tn1546-like elements and it could be speculated if this integration site is more prevalent among plasmids and is the reason for the preferred prevalence of vanA clusters on specific plasmids (Garcia-Migura et al., 2008). Results of a recent study about horizontal transferability of vanA plasmids among enterococci, other lactic acid bacteria and bifidobacteria revealed a preferred transfer into and a possible host restriction within the species E. faecium (Werner et al., 2010b). In contrast, vanB-type elements preferably integrate into the chromosome, but are mobile as part of integrative and conjugative elements ICE (Paulsen et al., 2003; Hegstad et al., 2010). Occasionally vanB resides on (transferable) plasmids (Rice et al., 1998; Zheng et al., 2009); as noticed recently associated with larger VanB-type VRE outbreaks (Sivertsen et al., 2011; Bjorkeng et al., 2011). Many surveillance studies failed to recognize a considerable reservoir of vanB among enterococcal colonizers in animals and humans, whereas recent real-time based studies targeting vanB or improved methods of detection revealed a considerable reservoir among intestinal colonizers, maybe also non-enterococcal bacteria (see above). In general, the supposed low expression of vancomycin resistance among vanB strains may have lead to an underestimation of its general prevalence, since in many screening studies comparably high vancomycin concentrations were used to select VRE (Poole et al., 2005; Hershberger et al., 2005). Rates of clinical vanB-type VRE are increasing, at least in some European countries 
during last years (Johnson et al., 2010; Soderblom et al., 2010; Bourdon et al., 2011) and a link to a supposed reservoir outside the clinical setting, for instance, among mammal intestinal colonizers is discussed also in areas where vanB-type vancomycin resistance is more prevalent (Christiansen et al., 2004; Johnson et al., 2010).

\section{Genereal conclusion}

Vancomycin resistance in enterococci has established as an important health care problem worldwide. Eight genotypes of acquired vancomycin resistance in enterococci are known. The vanA-type resistance encoded by transposon Tn1546 and Tn1546-derived elements is the most prevalent resistance determinant followed by vanB-type clusters which are mainly part of integrative and conjugative elements (ICE) mostly residing within the chromosome. The main van genotype reservoir is in E. faecium. Prevalence of VRE among the clinical setting varies in different parts of the world. Their increased incidence is linked to characteristic predisposing factors in affected patients but also to the bacteria themselves. The latter concerns a preferred spread of hospital-associated strain types among health care settings. These strains differ from commensal strains by their core genomes (different MLST types and clonal complexes) and an additional genomic content including specific (resistance) plasmids. However, countries and institutions having similar pre-conditions may experience different developments and changes in VRE prevalence are multifactorial and cannot be simply addressed to or predicted from specific factors and circumstances. VRE and their resistance determinants are still prevalent among commercial animal husbandry despite the glycopeptide avoparcin and other antimicrobial substances were banned for growth promotion in many parts of the world. Their role to feed the (vancomycin) resistance gene pool of hospital-associated strain types remains to be elucidated in further studies.

\section{References}

Aarestrup, F.M., 2000. Characterization of glycopeptide-resistant enterococcus faecium (GRE) from broilers and pigs in Denmark: genetic evidence that persistence of GRE in pig herds is associated with coselection by resistance to macrolides. J. Clin. Microbiol. 38, 2774-2777.

Aarestrup, F.M., Agerso, Y., Gerner-Smidt, P., Madsen, M., Jensen, L.B., 2000a. Comparison of antimicrobial resistance phenotypes and resistance genes in Enterococcus faecalis and Enterococcus faecium from humans in the community, broilers, and pigs in Denmark. Diagn. Microbiol. Infect. Dis. 37, 127-137.

Aarestrup, F.M., Bager, F., Andersen, J.S., 2000b. Association between the use of avilamycin for growth promotion and the occurrence of resistance among Enterococcus faecium from broilers: epidemiological study and changes over time. Microb. Drug Resist. 6, 71-75.

Abadia Patino, L., Christiansen, K., Bell, J., Courvalin, P., Perichon, B., 2004. VanE-type vancomycin-resistant Enterococcus faecalis clinical isolates from Australia. Antimicrob. Agents Chemother. 48, 4882-4885.

Abadia Patino, L., Courvalin, P., Perichon, B., 2002. vanE gene cluster of vancomycinresistant Enterococcus faecalis BM4405. J. Bacteriol. 184, 6457-6464. 
Agerso, Y., Lester, C.H., Porsbo, L.J., Orsted, I., Emborg, H.D., Olsen, K.E., Jensen, L.B., Heuer, O.E., Frimodt-Moller, N., Aarestrup, F.M., Hammerum, A.M., 2008. Vancomycin-resistant Enterococcus faecalis isolates from a Danish patient and two healthy human volunteers are possibly related to isolates from imported turkey meat. J. Antimicrob. Chemother. 62, 844-845.

Agerso, Y., Pedersen, A.G., Aarestrup, F.M., 2006. Identification of Tn5397-like and Tn916like transposons and diversity of the tetracycline resistance gene tet $(M)$ in enterococci from humans, pigs and poultry. J. Antimicrob. Chemother. 57, 832-839.

Arias, C.A., Courvalin, P., Reynolds, P.E., 2000. vanC cluster of vancomycin-resistant Enterococcus gallinarum BM4174. Antimicrob. Agents Chemother. 44, 1660-1666.

Arias, C.A., Martin-Martinez, M., Blundell, T.L., Arthur, M., Courvalin, P., Reynolds, P.E., 1999. Characterization and modelling of VanT: a novel, membrane-bound, serine racemase from vancomycin-resistant Enterococcus gallinarum BM4174. Mol. Microbiol. 31, 1653-1664.

Arias, C.A., Murray, B.E., 2008. Emergence and management of drug-resistant enterococcal infections. Expert. Rev. Anti. Infect. Ther. 6, 637-655.

Arsene, S., Leclercq, R., 2007. Role of a qnr-like gene in the intrinsic resistance of Enterococcus faecalis to fluoroquinolones. Antimicrob. Agents Chemother. 51, 3254-3258.

Arthur, M., Depardieu, F., Gerbaud, G., Galimand, M., Leclercq, R., Courvalin, P., 1997. The VanS sensor negatively controls VanR-mediated transcriptional activation of glycopeptide resistance genes of Tn1546 and related elements in the absence of induction. J. Bacteriol. 179, 97-106.

Arthur, M., Molinas, C., Depardieu, F., Courvalin, P., 1993. Characterization of Tn1546, a Tn3-related transposon conferring glycopeptide resistance by synthesis of depsipeptide peptidoglycan precursors in Enterococcus faecium BM4147. J. Bacteriol. 175, 117-127.

Arthur, M., Quintiliani, R., Jr., 2001. Regulation of VanA- and VanB-type glycopeptide resistance in enterococci. Antimicrob. Agents Chemother. 45, 375-381.

Ballard, S.A., Grabsch, E.A., Johnson, P.D., Grayson, M.L., 2005a. Comparison of three PCR primer sets for identification of vanB gene carriage in feces and correlation with carriage of vancomycin-resistant enterococci: interference by vanB-containing anaerobic bacilli. Antimicrob. Agents Chemother. 49, 77-81.

Ballard, S.A., Pertile, K.K., Lim, M., Johnson, P.D., Grayson, M.L., 2005b. Molecular characterization of vanB elements in naturally occurring gut anaerobes. Antimicrob. Agents Chemother. 49, 1688-1694.

Baptista, M., Rodrigues, P., Depardieu, F., Courvalin, P., Arthur, M., 1999. Single-cell analysis of glycopeptide resistance gene expression in teicoplanin-resistant mutants of a VanB-type Enterococcus faecalis. Mol. Microbiol. 32, 17-28.

Batchelor, M., Zhou, D., Cooper, M.A., Abell, C., Rayment, T., 2010. Vancomycin dimer formation between analogues of bacterial peptidoglycan surfaces probed by force spectroscopy. Org. Biomol. Chem. 8, 1142-1148.

Bates, J., 1997. Epidemiology of vancomycin-resistant enterococci in the community and the relevance of farm animals to human infection. J. Hosp. Infect. 37, 89-101.

Bates, J., Jordens, J.Z., Griffiths, D.T., 1994. Farm animals as a putative reservoir for vancomycin-resistant enterococcal infection in man. J. Antimicrob. Chemother. 34, 507-514. 
Bischoff, K., Jacob, J., 1996. [The sat4 streptothricin acetyltransferase gene of Campylobacter coli: its distribution in the environment and use as epidemiological marker]. Zentralbl. Hyg. Umweltmed. 198, 241-257.

Bjorkeng, E., Rasmussen, G., Sundsfjord, A., Sjoberg, L., Hegstad, K., Soderquist, B., 2011. Clustering of polyclonal VanB-type vancomycin-resistant Enterococcus faecium in a low-endemic area was associated with CC17-genogroup strains harbouring transferable vanB2-Tn5382 and pRUM-like repA containing plasmids with axe-txe plasmid addiction systems. APMIS 119, 247-258.

Boguslawska, J., Zycka-Krzesinska, J., Wilcks, A., Bardowski, J., 2009. Intra- and interspecies conjugal transfer of Tn916-like elements from Lactococcus lactis in vitro and in vivo. Appl. Environ. Microbiol. 75, 6352-6360.

Bonora, M.G., Ligozzi, M., Luzzani, A., Solbiati, M., Stepan, E., Fontana, R., 2006. Emergence of linezolid resistance in Enterococcus faecium not dependent on linezolid treatment. Eur. J. Clin. Microbiol. Infect. Dis. 25, 197-198.

Bonora, M.G., Olioso, D., Lo, C.G., Fontana, R., 2007. Phylogenetic analysis of vancomycinresistant Enterococcus faecium genotypes associated with outbreaks or sporadic infections in Italy. Microb. Drug Resist. 13, 171-177.

Bonten, M.J., Slaughter, S., Ambergen, A.W., Hayden, M.K., van, V.J., Nathan, C., Weinstein, R.A., 1998. The role of "colonization pressure" in the spread of vancomycinresistant enterococci: an important infection control variable. Arch. Intern. Med. $158,1127-1132$.

Bonten, M.J., Willems, R., Weinstein, R.A., 2001. Vancomycin-resistant enterococci: why are they here, and where do they come from? The Lancet Infectious Diseases 1, 314-325.

Borgen, K., Simonsen, G.S., Sundsfjord, A., Wasteson, Y., Olsvik, O., Kruse, H., 2000. Continuing high prevalence of VanA-type vancomycin-resistant enterococci on Norwegian poultry farms three years after avoparcin was banned. J. Appl. Microbiol. 89, 478-485.

Borgen, K., Sorum, M., Wasteson, Y., Kruse, H., 2001. VanA-type vancomycin-resistant enterococci (VRE) remain prevalent in poultry carcasses 3 years after avoparcin was banned. Int. J. Food Microbiol. 64, 89-94.

Borgen, K., Sorum, M., Wasteson, Y., Kruse, H., Oppegaard, H., 2002. Genetic linkage between erm(B) and vanA in Enterococcus hirae of poultry origin. Microb. Drug Resist. 8, 363-368.

Borgmann, S., Schulte, B., Wolz, C., Gruber, H., Werner, G., Goerke, C., Klare, I., Beyser, K., Heeg, P., Autenrieth, I.B., 2007. Discrimination between epidemic and nonepidemic glycopeptide-resistant E. faecium in a post-outbreak situation. J. Hosp. Infect. 67, 49-55.

Boumghar-Bourtchai, L., Dhalluin, A., Malbruny, B., Galopin, S., Leclercq, R., 2009. Influence of recombination on development of mutational resistance to linezolid in Enterococcus faecalis JH2-2. Antimicrob. Agents Chemother. AAC-

Bourdon, N., Berenger, R., Lepoultier, R., Mouet, A., Lesteven, C., Borgey, F., Fines-Guyon, M., Leclercq, R., Cattoir, V., 2010. Rapid detection of vancomycin-resistant enterococci from rectal swabs by the Cepheid Xpert vanA/vanB assay. Diagn. Microbiol. Infect. Dis. 67, 291-293.

Bourdon, N., Fines-Guyon, M., Thiolet, J.M., Maugat, S., Coignard, B., Leclercq, R., Cattoir, V., 2011. Changing trends in vancomycin-resistant enterococci in French hospitals, 2001-08. J. Antimicrob. Chemother. 66, 713-721. 
Bourgeois-Nicolaos, N., Massias, L., Couson, B., Butel, M.J., Andremont, A., DoucetPopulaire, F., 2007. Dose dependence of emergence of resistance to linezolid in Enterococcus faecalis in vivo. J Infect Dis 195, 1480-1488.

Boyd, D.A., Cabral, T., Van, C.P., Wylie, J., Mulvey, M.R., 2002. Molecular characterization of the vanE gene cluster in vancomycin-resistant Enterococcus faecalis N00-410 isolated in Canada. Antimicrob. Agents Chemother. 46, 1977-1979.

Boyd, D.A., Conly, J., Dedier, H., Peters, G., Robertson, L., Slater, E., Mulvey, M.R., 2000. Molecular characterization of the vanD gene cluster and a novel insertion element in a vancomycin-resistant enterococcus isolated in Canada. J. Clin. Microbiol. 38, 2392-2394.

Boyd, D.A., Du, T., Hizon, R., Kaplen, B., Murphy, T., Tyler, S., Brown, S., Jamieson, F., Weiss, K., Mulvey, M.R., 2006a. VanG-type vancomycin-resistant Enterococcus faecalis strains isolated in Canada. Antimicrob. Agents Chemother. 50, 2217-2221.

Boyd, D.A., Kibsey, P., Roscoe, D., Mulvey, M.R., 2004. Enterococcus faecium N03-0072 carries a new VanD-type vancomycin resistance determinant: characterization of the VanD5 operon. J. Antimicrob. Chemother. 54, 680-683.

Boyd, D.A., Miller, M.A., Mulvey, M.R., 2006b. Enterococcus gallinarum N04-0414 harbors a VanD-type vancomycin resistance operon and does not contain a D-alanine:Dalanine 2 (ddl2) gene. Antimicrob. Agents Chemother. 50, 1067-1070.

Boyd, D.A., Willey, B.M., Fawcett, D., Gillani, N., Mulvey, M.R., 2008. Molecular characterization of Enterococcus faecalis N06-0364 with low-level vancomycin resistance harboring a novel D-Ala-D-Ser gene cluster, vanL. Antimicrob. Agents Chemother. 52, 2667-2672.

Canton, R., Ruiz-Garbajosa, P., Chaves, R.L., Johnson, A.P., 2010. A potential role for daptomycin in enterococcal infections: what is the evidence? J. Antimicrob. Chemother. 65, 1126-1136.

Carias, L.L., Rudin, S.D., Donskey, C.J., Rice, L.B., 1998. Genetic linkage and cotransfer of a novel, vanB-containing transposon (Tn5382) and a low-affinity penicillin-binding protein 5 gene in a clinical vancomycin-resistant Enterococcus faecium isolate. J. Bacteriol. 180, 4426-4434.

Casadewall, B., Courvalin, P., 1999. Characterization of the vanD Glycopeptide Resistance Gene Cluster from Enterococcus faecium BM4339. J. Bacteriol. 181, 3644-3648.

Casetta, A., Hoi, A.B., de, C.G., Horaud, T., 1998. Diversity of structures carrying the highlevel gentamicin resistance gene (aac6-aph2) in Enterococcus faecalis strains isolated in France. Antimicrob. Agents Chemother. 42, 2889-2892.

Cetinkaya, Y., Falk, P., Mayhall, C.G., 2000. Vancomycin-resistant enterococci. Clin. Microbiol. Rev. 13, 686-707.

Chang, S., Sievert, D.M., Hageman, J.C., Boulton, M.L., Tenover, F.C., Downes, F.P., Shah, S., Rudrik, J.T., Pupp, G.R., Brown, W.J., Cardo, D., Fridkin, S.K., the VancomycinResistant Staphylococcus aureus Investigative Team, 2003. Infection with vancomycin-resistant Staphylococcus aureus containing the vanA resistance gene. N Engl J Med 348, 1342-1347.

Christiansen, K.J., Tibbett, P.A., Beresford, W., Pearman, J.W., Lee, R.C., Coombs, G.W., Kay, I.D., O'Brien, F.G., Palladino, S., Douglas, C.R., Montgomery, P.D., Orrell, T., Peterson, A.M., Kosaras, F.P., Flexman, J.P., Heath, C.H., McCullough, C.A., 2004. Eradication of a large outbreak of a single strain of vanB vancomycin-resistant 
Enterococcus faecium at a major Australian teaching hospital. Infect. Control Hosp. Epidemiol. 25, 384-390.

Clark, N.C., Weigel, L.M., Patel, J.B., Tenover, F.C., 2005. Comparison of Tn1546-like elements in vancomycin-resistant Staphylococcus aureus isolates from Michigan and Pennsylvania. Antimicrob. Agents Chemother. 49, 470-472.

Coque, T.M., Tomayko, J.F., Ricke, S.C., Okhyusen, P.C., Murray, B.E., 1996. Vancomycinresistant enterococci from nosocomial, community, and animal sources in the United States. Antimicrob. Agents Chemother. 40, 2605-2609.

Courvalin, P., 2005. Genetics of glycopeptide resistance in gram-positive pathogens. Int. J. Med. Microbiol. 294, 479-486.

Courvalin, P., 2006. Vancomycin resistance in gram-positive cocci. Clin. Infect. Dis. 42 Suppl 1, S25-S34.

Cui, L., Lian, J.Q., Neoh, H.M., Reyes, E., Hiramatsu, K., 2005. DNA microarray-based identification of genes associated with glycopeptide resistance in Staphylococcus aureus. Antimicrob. Agents Chemother. 49, 3404-3413.

Dahl, K.H., Mater, D.D., Flores, M.J., Johnsen, P.J., Midtvedt, T., Corthier, G., Sundsfjord, A., 2007. Transfer of plasmid and chromosomal glycopeptide resistance determinants occurs more readily in the digestive tract of mice than in vitro and exconjugants can persist stably in vivo in the absence of glycopeptide selection. J. Antimicrob. Chemother. 59, 478-486.

Dahl, K.H., Rokenes, T.P., Lundblad, E.W., Sundsfjord, A., 2003. Nonconjugative transposition of the vanB-containing Tn5382-like element in Enterococcus faecium. Antimicrob. Agents Chemother. 47, 786-789.

Dahl, K.H., Sundsfjord, A., 2003. Transferable vanB2 Tn5382-containing elements in fecal streptococcal strains from veal calves. Antimicrob. Agents Chemother. 47, 25792583 .

David, V., Bozdogan, B., Mainardi, J.L., Legrand, R., Gutmann, L., Leclercq, R., 2004. Mechanism of intrinsic resistance to vancomycin in Clostridium innocuum NCIB 10674. J. Bacteriol. 186, 3415-3422.

de Vries, L.E., Christensen, H., Skov, R.L., Aarestrup, F.M., Agerso, Y., 2009. Diversity of the tetracycline resistance gene tet(M) and identification of Tn916- and Tn5801-like (Tn6014) transposons in Staphylococcus aureus from humans and animals. J. Antimicrob. Chemother. 64, 490-500.

Deghorain, M., Goffin, P., Fontaine, L., Mainardi, J.L., Daniel, R., Errington, J., Hallet, B., Hols, P., 2007. Selectivity for D-lactate incorporation into the peptidoglycan precursors of Lactobacillus plantarum: role of Aad, a VanX-like D-alanyl-D-alanine dipeptidase. J. Bacteriol. 189, 4332-4337.

Depardieu, F., Bonora, M.G., Reynolds, P.E., Courvalin, P., 2003a. The vanG glycopeptide resistance operon from Enterococcus faecalis revisited. Mol. Microbiol. 50, 931-948.

Depardieu, F., Foucault, M.L., Bell, J., Dubouix, A., Guibert, M., Lavigne, J.P., Levast, M., Courvalin, P., 2009. New combinations of mutations in VanD-Type vancomycinresistant Enterococcus faecium, Enterococcus faecalis, and Enterococcus avium strains. Antimicrob. Agents Chemother. 53, 1952-1963.

Depardieu, F., Reynolds, P.E., Courvalin, P., 2003b. VanD-type vancomycin-resistant Enterococcus faecium 10/96A. Antimicrob. Agents Chemother. 47, 7-18. 
Depardieu, F., Kolbert, M., Pruul, H., Bell, J., Courvalin, P., 2004. vanD-Type vancomycinresistant Enterococcus faecium and Enterococcus faecalis. Antimicrob. Agents Chemother. 48, 3892-3904.

Deplano, A., Denis, O., Nonhoff, C., Rost, F., Byl, B., Jacobs, F., Vankerckhoven, V., Goossens, H., Struelens, M.J., 2007. Outbreak of hospital-adapted clonal complex-17 vancomycin-resistant Enterococcus faecium strain in a haematology unit: role of rapid typing for early control. J. Antimicrob. Chemother. 60, 849-854.

Derbise, A., Aubert, S., El, S.N., 1997. Mapping the regions carrying the three contiguous antibiotic resistance genes aadE, sat4, and aphA-3 in the genomes of staphylococci. Antimicrob. Agents Chemother. 41, 1024-1032.

Derbise, A., Dyke, K.G., El Solh, N., 1996. Characterization of a Staphylococcus aureus transposon, Tn5405, located within Tn5404 and carrying the aminoglycoside resistance genes, aphA-3 and aadE. Plasmid 35, 174-188.

Deshpande, L.M., Fritsche, T.R., Moet, G.J., Biedenbach, D.J., Jones, R.N., 2007. Antimicrobial resistance and molecular epidemiology of vancomycin-resistant enterococci from North America and Europe: a report from the SENTRY antimicrobial surveillance program. Diagn. Microbiol. Infect. Dis. 58, 163-170.

Domingo, M.C., Huletsky, A., Boissinot, M., Bernard, K.A., Picard, F.J., Bergeron, M.G., 2008. Ruminococcus gauvreauii sp. nov., a glycopeptide-resistant species isolated from a human faecal specimen. Int. J. Syst. Evol. Microbiol. 58, 1393-1397.

Domingo, M.C., Huletsky, A., Giroux, R., Boissinot, K., Picard, F.J., Lebel, P., Ferraro, M.J., Bergeron, M.G., 2005. High prevalence of glycopeptide resistance genes vanB, vanD, and vanG not associated with enterococci in human fecal flora. Antimicrob. Agents Chemother. 49, 4784-4786.

Domingo, M.C., Huletsky, A., Giroux, R., Picard, F.J., Bergeron, M.G., 2007. vanD and vanGLike gene clusters in a Ruminococcus species isolated from human bowel flora. Antimicrob. Agents Chemother. 51, 4111-4117.

Donabedian, S.M., Perri, M.B., Abdujamilova, N., Gordoncillo, M.J., Naqvi, A., Reyes, K.C., Zervos, M.J., Bartlett, P., 2010. Characterization of vancomycin-resistant Enterococcus faecium isolated from swine in three Michigan counties. J. Clin. Microbiol.

Donskey, C.J., 2004. The role of the intestinal tract as a reservoir and source for transmission of nosocomial pathogens. Clin. Infect. Dis. 39, 219-226.

Dutta, I., Reynolds, P.E., 2002. Biochemical and genetic characterization of the vanC-2 vancomycin resistance gene cluster of Enterococcus casseliflavus ATCC 25788. Antimicrob. Agents Chemother. 46, 3125-3132.

EARSS, 2009. EARSS Annual report 2008. EARSS Annual report 2008 10, 1-180.

Facklam, R.R., Carvalho, M.d.G.S., Teixeira, L.M., 2002. History, taxonomy, biochemical characteristics, and antibiotic susceptibility testing of enterococci. In: Gilmore, M.S. (Eds), The enterococci: Pathogenesis, molecular biology, and antibiotic resistance. ASM Press, Washington, D.C., pp. 1-54.

Fang, H., Nord, C.E., Ullberg, M., 2010. Screening for vancomycin-resistant enterococci: results of a survey in Stockholm. APMIS 118, 413-417.

Fines, M., Perichon, B., Reynolds, P., Sahm, D.F., Courvalin, P., 1999. VanE, a new type of acquired glycopeptide resistance in Enterococcus faecalis BM4405. Antimicrob. Agents Chemother. 43, 2161-2164. 
Finks, J., Wells, E., Dyke, T.L., Husain, N., Plizga, L., Heddurshetti, R., Wilkins, M., Rudrik, J., Hageman, J., Patel, J., Miller, C., 2009. Vancomycin-resistant Staphylococcus aureus, Michigan, USA, 2007. Emerg. Infect. Dis. 15, 943-945.

Fischer, A., Yang, S.J., Bayer, A.S., Vaezzadeh, A.R., Herzig, S., Stenz, L., Girard, M., Sakoulas, G., Scherl, A., Yeaman, M.R., Proctor, R.A., Schrenzel, J., Francois, P., 2011. Daptomycin resistance mechanisms in clinically derived Staphylococcus aureus strains assessed by a combined transcriptomics and proteomics approach. J. Antimicrob. Chemother. 66, 1696-1711.

Foglia, G., Del, G.M., Vignaroli, C., Bagnarelli, P., Varaldo, P.E., Pantosti, A., Biavasco, F., 2003. Molecular analysis of Tn1546-like elements mediating high-level vancomycin resistance in Enterococcus gallinarum. J. Antimicrob. Chemother. 52, 772-775.

Foucault, M.L., Courvalin, P., Grillot-Courvalin, C., 2009. Fitness cost of VanA-type vancomycin resistance in methicillin-resistant Staphylococcus aureus. Antimicrob. Agents Chemother. 53, 2354-2359.

Foucault, M.L., Depardieu, F., Courvalin, P., Grillot-Courvalin, C., 2010. Inducible expression eliminates the fitness cost of vancomycin resistance in enterococci. Proc. Natl. Acad. Sci. U. S. A 107, 16964-16969.

Fraimow, H., Knob, C., Herrero, I.A., Patel, R., 2005. Putative VanRS-like two-component regulatory system associated with the inducible glycopeptide resistance cluster of Paenibacillus popilliae. Antimicrob. Agents Chemother. 49, 2625-2633.

Freitas, A.R., Coque, T.M., Novais, C., Hammerum, A.M., Lester, C.H., Zervos, M.J., Donabedian, S., Jensen, L.B., Francia, M.V., Baquero, F., Peixe, L., 2011b. Human and swine hosts share vancomycin-resistant Enterococcus faecium CC17 and CC5 and Enterococcus faecalis CC2 clonal clusters harboring Tn1546 on indistinguishable plasmids. J. Clin. Microbiol. 49, 925-931.

Freitas, A.R., Coque, T.M., Novais, C., Hammerum, A.M., Lester, C.H., Zervos, M.J., Donabedian, S., Jensen, L.B., Francia, M.V., Baquero, F., Peixe, L., 2011a. Human and swine hosts share vancomycin-resistant Enterococcus faecium CC17 and CC5 and Enterococcus faecalis CC2 clonal clusters harboring Tn1546 on indistinguishable plasmids. J. Clin. Microbiol. 49, 925-931.

Freitas, A.R., Novais, C., Ruiz-Garbajosa, P., Coque, T.M., Peixe, L., 2009. Clonal expansion within clonal complex 2 and spread of vancomycin-resistant plasmids among different genetic lineages of Enterococcus faecalis from Portugal. J. Antimicrob. Chemother. 63, 1104-1111.

Galloway-Pena, J.R., Nallapareddy, S.R., Arias, C.A., Eliopoulos, G.M., Murray, B.E., 2009. Analysis of clonality and antibiotic resistance among early clinical isolates of Enterococcus faecium in the United States. J. Infect. Dis. 15, 1566-1573.

Galloway-Pena, J.R., Rice, L.B., Murray, B.E., 2011. Analysis of PBP5 of early U.S. isolates of Enterococcus faecium: Sequence variation alone does not explain increasing ampicillin resistance over time. Antimicrob. Agents Chemother. 55, 3272-3277.

Garcia-Migura, L., Hasman, H., Svendsen, C., Jensen, L.B., 2008. Relevance of hot spots in the evolution and transmission of Tn1546 in glycopeptide-resistant Enterococcus faecium (GREF) from broiler origin. J. Antimicrob. Chemother. 62, 681-687.

Garcia-Migura, L., Liebana, E., Jensen, L.B., 2007. Transposon characterization of vancomycin-resistant Enterococcus faecium (VREF) and dissemination of resistance associated with transferable plasmids. J. Antimicrob. Chemother. 60, 263-268. 
Gfeller, K.Y., Roth, M., Meile, L., Teuber, M., 2003. Sequence and genetic organization of the 19.3-kb erythromycin- and dalfopristin-resistance plasmid pLME300 from Lactobacillus fermentum ROT1. Plasmid 50, 190-201.

Ghidan, A., Kaszanyitzky, E.J., Dobay, O., Nagy, K., Amyes, S.G., Rozgonyi, F., 2008. Distribution and genetic relatedness of vancomycin-resistant enterococci (VRE) isolated from healthy slaughtered chickens in Hungary from 2001 to 2004. Acta Vet. Hung. 56, 13-25.

Goffin, P., Deghorain, M., Mainardi, J.L., Tytgat, I., Champomier-Verges, M.C., Kleerebezem, M., Hols, P., 2005. Lactate racemization as a rescue pathway for supplying D-lactate to the cell wall biosynthesis machinery in Lactobacillus plantarum. J. Bacteriol. 187, 6750-6761.

Grabsch, E.A., Chua, K., Xie, S., Byrne, J., Ballard, S.A., Ward, P.B., Grayson, M.L., 2008a. Improved detection of vanB2-containing Enterococcus faecium with vancomycin susceptibility by Etest using oxgall supplementation. J. Clin. Microbiol. 46, 19611964.

Grabsch, E.A., Ghaly-Derias, S., Gao, W., Howden, B.P., 2008b. Comparative study of selective chromogenic (chromID VRE) and bile esculin agars for isolation and identification of vanB-containing vancomycin-resistant enterococci from feces and rectal swabs. J. Clin. Microbiol. 46, 4034-4036.

Graham, M., Ballard, S.A., Grabsch, E.A., Johnson, P.D.R., Grayson, M.L., 2008. High rates of fecal carriage of nonenterococcal vanB in both children and adults. Antimicrob. Agents Chemother. 52, 1195-1197.

Guardabassi, L., Christensen, H., Hasman, H., Dalsgaard, A., 2004. Members of the genera Paenibacillus and Rhodococcus harbor genes homologous to enterococcal glycopeptide resistance genes vanA and vanB. Antimicrob. Agents Chemother. 48, 4915-4918.

Guardabassi, L., Agerso, Y., 2006. Genes homologous to glycopeptide resistance vanA are widespread in soil microbial communities. FEMS Microbiology Letters 259, 221225.

Guardabassi, L., Perichon, B., van Heijenoort, J., Blanot, D., Courvalin, P., 2005. Glycopeptide resistance vanA operons in Paenibacillus strains isolated from soil. Antimicrob. Agents Chemother. 49, 4227-4233.

Haenni, M., Saras, E., Chatre, P., Meunier, D., Martin, S., Lepage, G., Menard, M.F., Lebreton, P., Rambaud, T., Madec, J.Y., 2009. vanA in Enterococcus faecium, Enterococcus faecalis, and Enterococcus casseliflavus detected in French cattle. Foodborne. Pathog. Dis. 6, 1107-1111.

Hallgren, A., Saeedi, B., Nilsson, M., Monstein, H.J., Isaksson, B., Hanberger, H., Nilsson, L.E., 2003. Genetic relatedness among Enterococcus faecalis with transposonmediated high-level gentamicin resistance in Swedish intensive care units. J. Antimicrob. Chemother. 52, 162-167.

Hammerum, A.M., Lester, C.H., Heuer, O.E., 2010. Antimicrobial-resistant enterococci in animals and meat: a human health hazard? Foodborne. Pathog. Dis. 7, 1137-1146.

Hegstad, K., Mikalsen, T., Coque, T.M., Werner, G., Sundsfjord, A., 2010. Mobile genetic elements and their contribution to the emergence of antimicrobial resistant Enterococcus faecalis and Enterococus faecium. Clin. Microbiol. Infect. 16, 541-554. 
Heikens, E., van Schaik, W., Leavis, H.L., Bonten, M.J.M., Willems, R.J.L., 2008. Identification of a novel genomic island specific to hospital-acquired clonal complex 17 Enterococcus faecium isolates. Appl. Environ. Microbiol. 74, 7094-7097.

Hendrickx, A.P., Willems, R.J., Bonten, M.J., van, S.W., 2009. LPxTG surface proteins of enterococci. Trends Microbiol. 17, 423-430.

Hendrickx, A.P.A., Bonten, M.J.M., van Luit-Asbroek, M., Schapendonk, C.M.E., Kragten, A.H.M., Willems, R.J.L., 2008. Expression of two distinct types of pili by a hospitalacquired Enterococcus faecium isolate. Microbiology 154, 3212-3223.

Hendrickx, A.P.A., Van Wamel, W.J.B., Posthuma, G., Bonten, M.J.M., Willems, R.J.L., 2007. Five genes encoding surface exposed LPXTG proteins are enriched in hospitaladapted Enterococcus faecium Clonal Complex-17 isolates. J. Bacteriol. 189, 83218332.

Hershberger, E., Oprea, S.F., Donabedian, S.M., Perri, M., Bozigar, P., Bartlett, P., Zervos, M.J., 2005. Epidemiology of antimicrobial resistance in enterococci of animal origin. J. Antimicrob. Chemother. 55, 127-130.

Hooper, D.C., 2002. Fluoroquinolone resistance among Gram-positive cocci. The Lancet Infectious Diseases 2, 530-538.

Horinouchi, S., Weisblum, B., 1980. Posttranscriptional modification of mRNA conformation: mechanism that regulates erythromycin-induced resistance. Proc. Natl. Acad. Sci. U. S. A 77, 7079-7083.

Horodniceanu, T., Bougueleret, L., El-Solh, N., Bieth, G., Delbos, F., 1979. High-level, plasmid-borne resistance to gentamicin in Streptococcus faecalis subsp. zymogenes. Antimicrob. Agents Chemother. 16, 686-689.

Howden, B.P., Davies, J.K., Johnson, P.D., Stinear, T.P., Grayson, M.L., 2010. Reduced vancomycin susceptibility in Staphylococcus aureus, including vancomycinintermediate and heterogeneous vancomycin-intermediate strains: resistance mechanisms, laboratory detection, and clinical implications. Clin. Microbiol. Rev. 23, 99-139.

Hsieh, Y.C., Lee, W.S., Ou, T.Y., Hsueh, P.R., 2010. Clonal spread of CC17 vancomycinresistant Enterococcus faecium with multilocus sequence type 78 (ST78) and a novel ST444 in Taiwan. Eur. J. Clin. Microbiol. Infect. Dis. 29, 25-30.

Hsieh, Y.C., Ou, T.Y., Teng, S.O., Lee, W.C., Lin, Y.C., Wang, J.T., Chang, S.C., Lee, W.S., 2009. Vancomycin-resistant enterococci in a tertiary teaching hospital in Taiwan. J. Microbiol. Immunol. Infect. 42, 63-68.

Huh, J.Y., Lee, W.G., Lee, K., Shin, W.S., Yoo, J.H., 2004. Distribution of insertion sequences associated with Tn1546-like elements among Enterococcus faecium isolates from patients in Korea. J. Clin. Microbiol. 42, 1897-1902.

Jackson, C.R., Fedorka-Cray, P.J., Barrett, J.B., Ladely, S.R., 2004. Genetic relatedness of highlevel aminoglycoside-resistant enterococci isolated from poultry carcasses. Avian Dis. $48,100-107$.

Jackson, C.R., Fedorka-Cray, P.J., Barrett, J.B., Ladely, S.R., 2005. High-level aminoglycoside resistant enterococci isolated from swine. Epidemiol. Infect. 133, 367-371.

Jacob, J., Evers, S., Bischoff, K., Carlier, C., Courvalin, P., 1994. Characterization of the sat4 gene encoding a streptothricin acetyltransferase in Campylobacter coli BE/G4. FEMS Microbiol. Lett. 120, 13-17.

Jacoby, G.A., 2005. Mechanisms of resistance to quinolones. Clin. Infect. Dis. 41 Suppl 2, S120-S126. 
Jasni, A.S., Mullany, P., Hussain, H., Roberts, A.P., 2010. Demonstration of conjugative transposon (Tn5397)-mediated horizontal gene transfer between Clostridium difficile and Enterococcus faecalis. Antimicrob. Agents Chemother. 54, 4924-4926.

Jensen, L.B., Ahrens, P., Dons, L., Jones, R.N., Hammerum, A.M., Aarestrup, F.M., 1998. Molecular analysis of Tn1546 in Enterococcus faecium isolated from animals and humans. J. Clin. Microbiol. 36, 437-442.

Johnson, P.D., Ballard, S.A., Grabsch, E.A., Stinear, T.P., Seemann, T., Young, H.L., Grayson, M.L., Howden, B.P., 2010. A sustained hospital outbreak of vancomycin-resistant Enterococcus faecium bacteremia due to emergence of vanB E. faecium sequence type 203. J. Infect. Dis. 202, 1278-1286.

Jones, R.N., Deshpande, L.M., 2004. Are Enterococcus faecalis strains with vat(E) in poultry a reservoir for human streptogramin resistance? vat(E) occurrence in human enterococcal bloodstream infections in North America (SENTRY Antimicrobial Surveillance Program, 2002). Antimicrob. Agents Chemother. 48, 360-361.

Jung, W.K., Lim, J.Y., Kwon, N.H., Kim, J.M., Hong, S.K., Koo, H.C., Kim, S.H., Park, Y.H., 2007. Vancomycin-resistant enterococci from animal sources in Korea. Int. J. Food Microbiol. 113, 102-107.

Jung, Y.H., Shin, E.S., Kim, O., Yoo, J.S., Lee, K.M., Yoo, J.I., Chung, G.T., Lee, Y.S., 2010. Characterization of two newly identified genes, vgaD and vatG, conferring resistance to streptogramin $\mathrm{A}$ in Enterococcus faecium. Antimicrob. Agents Chemother. 54, 4744-4749.

JUREEN, R., MOHN, S.C., Harthug, S., HAARR, L., LANGELAND, N., 2004. Role of penicillin-binding protein $5 \mathrm{C}$-terminal amino acid substitutions in conferring ampicillin resistance in Norwegian clinical strains of Enterococcus faecium. APMIS 112, 291-298.

Karlowsky, J.A., Jones, M.E., Draghi, D.C., Thornsberry, C., Sahm, D.F., Volturo, G.A., 2004. Prevalence and antimicrobial susceptibilities of bacteria isolated from blood cultures of hospitalized patients in the United States in 2002. Ann. Clin. Microbiol. Antimicrob. 3, 7-

Karlowsky, J.A., Zhanel, G.G., Hoban, D.J., 1999. Vancomycin-resistant enterococci (VRE) colonization of high-risk patients in tertiary care Canadian hospitals. Canadian VRE Surveillance Group. Diagn. Microbiol. Infect. Dis. 35, 1-7.

Kawalec, M., Gniadkowski, M., Kedzierska, J., Skotnicki, A., Fiett, J., Hryniewicz, W., 2001 b. Selection of a teicoplanin-resistant Enterococcus faecium mutant during an outbreak caused by vancomycin-resistant enterococci with the vanB phenotype. J. Clin. Microbiol. 39, 4274-4282.

Kawalec, M., Gniadkowski, M., Kedzierska, J., Skotnicki, A., Fiett, J., Hryniewicz, W., 2001a. Selection of a teicoplanin-resistant Enterococcus faecium mutant during an outbreak caused by vancomycin-resistant enterococci with the vanB phenotype. J. Clin. Microbiol. 39, 4274-4282.

Kawalec, M., Kedzierska, J., Gajda, A., Sadowy, E., Wegrzyn, J., Naser, S., Skotnicki, A.B., Gniadkowski, M., Hryniewicz, W., 2007. Hospital outbreak of vancomycin-resistant enterococci caused by a single clone of Enterococcus raffinosus and several clones of Enterococcus faecium. Clinical Microbiology and Infection 13, 893-901.

Kerr, I.D., Reynolds, E.D., Cove, J.H., 2005. ABC proteins and antibiotic drug resistance: is it all about transport? Biochem. Soc. Trans. 33, 1000-1002. 
Klare, I., Badstubner, D., Konstabel, C., Bohme, G., Claus, H., Witte, W., 1999. Decreased incidence of VanA-type vancomycin-resistant enterococci isolated from poultry meat and from fecal samples of humans in the community after discontinuation of avoparcin usage in animal husbandry. Microb. Drug Resist. 5, 45-52.

Klare, I., Heier, H., Claus, H., Bohme, G., Marin, S., Seltmann, G., Hakenbeck, R., Antanassova, V., Witte, W., 1995a. Enterococcus faecium strains with vanAmediated high-level glycopeptide resistance isolated from animal foodstuffs and fecal samples of humans in the community. Microb. Drug Resist. 1, 265-272.

Klare, I., Heier, H., Claus, H., Reissbrodt, R., Witte, W., 1995b. vanA-mediated high-level glycopeptide resistance in Enterococcus faecium from animal husbandry. FEMS Microbiol. Lett. 125, 165-171.

Klare, I., Heier, H., Claus, H., Witte, W., 1993. Environmental strains of Enterococcus faecium with inducible high-level resistance to glycopeptides. FEMS Microbiol. Lett. 106, 23-29.

Klare, I., Konstabel, C., Badstübner, D., Werner, G., Witte, W., 2003. Occurrence and spread of antibiotic resistances in Enterococcus faecium. Int. J. Food Microbiol. 88, 269-290.

Klare, I., Konstabel, C., Mueller-Bertling, S., Werner, G., Strommenger, B., Kettlitz, C., Borgmann, S., Schulte, B., Jonas, D., Serr, A., Fahr, A., Eigner, U., Witte, W., 2005. Spread of ampicillin/vancomycin-resistant Enterococcus faecium of the epidemicvirulent clonal complex-17 carrying the genes esp and hyl in German hospitals. European Journal of Clinical Microbiology \& Infectious Diseases 24, 815-825.

Klare, I., Werner, G., Witte, W., 2010. Enterococci with vancomycin resistance from German hospitals in 2008/2009 (German). Epidemiologisches Bulletin 2010, 427-437.

Klare, I., Witte, W., 1998. VRE: animal reservoirs and food. In: Brun-Buisson, C., Eliopoulos, G.M., Leclercq, R. (Eds), Bacterial resistance to glycopeptides. Flammarion Médecine-Sciences, Paris, pp. 83-93.

Klein, G., Pack, A., Reuter, G., 1998. Antibiotic resistance patterns of enterococci and occurrence of vancomycin-resistant enterococci in raw minced beef and pork in Germany. Appl. Environ. Microbiol. 64, 1825-1830.

Ko, K.S., Baek, J.Y., Lee, J.Y., Oh, W.S., Peck, K.R., Lee, N., Lee, W.G., Lee, K., Song, J.H., 2005. Molecular characterization of vancomycin-resistant Enterococcus faecium isolates from Korea. J. Clin. Microbiol. 43, 2303-2306.

Koh, T.H., Hsu, L.Y., Chiu, L.L., Lin, R.V.T.P., 2006. Emergence of epidemic clones of vancomycin-resistant Enterococcus faecium in Singapore. Journal of Hospital Infection 63, 234-236.

Koh, T.H., Low, B.S., Leo, N., Hsu, L.Y., Lin, R.T., Krishnan, P., Chan, D., Nadarajah, M., Toh, S.L., Ong, K.H., 2009. Molecular epidemiology of vancomycin-resistant enterococci in Singapore. Pathology 41, 676-680.

Kojima, A., Morioka, A., Kijima, M., Ishihara, K., Asai, T., Fujisawa, T., Tamura, Y., Takahashi, T., 2010. Classification and antimicrobial susceptibilities of enterococcus species isolated from apparently healthy food-producing animals in Japan. Zoonoses. Public Health 57, 137-141.

Kruse, H., Johansen, B.K., Rorvik, L.M., Schaller, G., 1999. The use of avoparcin as a growth promoter and the occurrence of vancomycin-resistant Enterococcus species in Norwegian poultry and swine production. Microb. Drug Resist. 5, 135-139. 
Kuzin, A.P., Sun, T., Jorczak-Baillass, J., Healy, V.L., Walsh, C.T., Knox, J.R., 2000. Enzymes of vancomycin resistance: the structure of D-alanine-D-lactate ligase of naturally resistant Leuconostoc mesenteroides. Structure. 8, 463-470.

Kwong, S.M., Lim, R., Lebard, R.J., Skurray, R.A., Firth, N., 2008. Analysis of the pSK1 replicon, a prototype from the staphylococcal multiresistance plasmid family. Microbiology 154, 3084-3094.

Larsen, J., Schonheyder, H.C., Lester, C.H., Olsen, S.S., Porsbo, L.J., Garcia-Migura, L., Jensen, L.B., Bisgaard, M., Hammerum, A.M., 2010. Porcine-origin gentamicinresistant Enterococcus faecalis in Humans, Denmark. Emerg. Infect. Dis. 16, 682684.

Lauderdale, T.L., Shiau, Y.R., Wang, H.Y., Lai, J.F., Huang, I.W., Chen, P.C., Chen, H.Y., Lai, S.S., Liu, Y.F., Ho, M., 2007. Effect of banning vancomycin analogue avoparcin on vancomycin-resistant enterococci in chicken farms in Taiwan. Environmental Microbiology 9, 819-823.

Launay, A., Ballard, S.A., Johnson, P.D.R., Grayson, M.L., Lambert, T., 2006. Transfer of vancomycin resistance transposon Tn1549 from Clostridium symbiosum to Enterococcus spp. in the gut of gnotobiotic mice. Antimicrob. Agents Chemother. $50,1054-1062$.

Laverde Gomez, J.A., van, S.W., Freitas, A.R., Coque, T.M., Weaver, K.E., Francia, M.V., Witte, W., Werner, G., 2010. A multiresistance megaplasmid pLG1 bearing a hyl(Efm) genomic island in hospital Enterococcus faecium isolates. Int. J. Med. Microbiol.

Laverde Gomez, J.A., van, S.W., Freitas, A.R., Coque, T.M., Weaver, K.E., Francia, M.V., Witte, W., Werner, G., 2011. A multiresistance megaplasmid pLG1 bearing a hylEfm genomic island in hospital Enterococcus faecium isolates. Int. J. Med. Microbiol. 301, 165-175.

Leavis, H.L., Willems, R.J., van Wamel, W.J., Schuren, F.H., Caspers, M.P., Bonten, M.J., 2007. Insertion sequence-driven diversification creates a globally dispersed emerging multiresistant subspecies of E. faecium. PLoS. Pathog. 3, e7-75.

Leavis, H.L., Willems, R.J.L., Top, J., Bonten, M.J.M., 2006. High-Level ciprofloxacin resistance from point mutations in gyrA and parC confined to global hospitaladapted clonal lineage CC17 of Enterococcus faecium. J. Clin. Microbiol. 44, 10591064.

Leclercq, R., Derlot, E., Duval, J., Courvalin, P., 1988. Plasmid-mediated resistance to vancomycin and teicoplanin in Enterococcus faecium. N. Engl. J. Med. 319, 157-161.

Leclercq, R., Derlot, E., Weber, M., Duval, J., Courvalin, P., 1989. Transferable vancomycin and teicoplanin resistance in Enterococcus faecium. Antimicrob. Agents Chemother. 33, 10-15.

Lee, S.Y., Park, K.G., Lee, G.D., Park, J.J., Park, Y.J., 2010. Comparison of Seeplex VRE detection kit with ChromID VRE agar for detection of vancomycin-resistant enterococci in rectal swab specimens. Ann. Clin. Lab Sci. 40, 163-166.

Lester, C.H., Hammerum, A.M., 2010. Transfer of vanA from an Enterococcus faecium isolate of chicken origin to a CC17 E. faecium isolate in the intestine of cephalosporin-treated mice. J. Antimicrob. Chemother. 65, 1534-1536.

Lester, C.H., Olsen, S.S., Schonheyder, H.C., Hansen, D.S., Tvede, M., Holm, A., Arpi, M., Friis-Moller, A., Jensen, K.T., Kemp, M., Hammerum, A.M., 2009. Typing of vancomycin-resistant enterococci obtained from patients at Danish hospitals and 
detection of a genomic island specific to CC17 Enterococcus faecium. Int. J. Antimicrob. Agents 35, 312-314.

Lester, C.H., Sandvang, D., Olsen, S.S., Schonheyder, H.C., Jarlov, J.O., Bangsborg, J., Hansen, D.S., Jensen, T.G., Frimodt-Moller, N., Hammerum, A.M., 2008. Emergence of ampicillin-resistant Enterococcus faecium in Danish hospitals. J. Antimicrob. Chemother. 62, 1203-1206.

Lester, C.H., Frimodt-Moller, N., Sorensen, T.L., Monnet, D.L., Hammerum, A.M., 2006. In vivo transfer of the vanA resistance gene from an Enterococcus faecium isolate of animal origin to an E. faecium isolate of human origin in the intestines of human volunteers. Antimicrob. Agents Chemother. 50, 596-599.

Lim, S.K., Kim, T.S., Lee, H.S., Nam, H.M., Joo, Y.S., Koh, H.B., 2006. Persistence of vanAtype Enterococcus faecium in Korean livestock after ban on avoparcin. Microbial Drug Resistance 12, 136-139.

Lobritz, M., Hutton-Thomas, R., Marshall, S., Rice, L.B., 2003. Recombination proficiency influences frequency and locus of mutational resistance to linezolid in Enterococcus faecalis. Antimicrob. Agents Chemother. 47, 3318-3320.

Lopez, M., Hormazabal, J.C., Maldonado, A., Saavedra, G., Baquero, F., Silva, J., Torres, C., Del, C.R., 2009. Clonal dissemination of Enterococcus faecalis ST201 and Enterococcus faecium CC17-ST64 containing Tn5382-vanB2 among 16 hospitals in Chile. Clin. Microbiol. Infect. 15, 586-588.

Mahbub, A.M., Kobayashi, N., Ishino, M., Sumi, A., Kobayashi, K., Uehara, N., Watanabe, N., 2005. Detection of a novel aph(2") allele (aph[2"]-Ie) conferring high-level gentamicin resistance and a spectinomycin resistance gene ant(9)-Ia (aad 9) in clinical isolates of enterococci. Microb. Drug Resist. 11, 239-247.

Mak, A., Miller, M.A., Chong, G., Monczak, Y., 2009. Comparison of PCR and culture for screening of vancomycin-resistant Enterococci: highly disparate results for vanA and vanB. J. Clin. Microbiol. 47, 4136-4137.

Mammina, C., Di Noto, A.M., Costa, A., Nastasi, A., 2005. VanB-VanC1 Enterococcus gallinarum, Italy. Emerg. Infect. Dis. 11, 1491-1492.

Manson, J.M., Keis, S., Smith, J.M., Cook, G.M., 2003a. Characterization of a vancomycinresistant Enterococcus faecalis (VREF) isolate from a dog with mastitis: further evidence of a clonal lineage of VREF in New Zealand. J. Clin. Microbiol. 41, 33313333.

Manson, J.M., Smith, J.M., Cook, G.M., 2004. Persistence of vancomycin-resistant enterococci in New Zealand broilers after discontinuation of avoparcin use. Appl. Environ. Microbiol. 70, 5764-5768.

Manson, J.M., Keis, S., Smith, J.M.B., Cook, G.M., 2003b. A clonal lineage of VanA-type Enterococcus faecalis predominates in vancomycin-resistant enterococci isolated in New Zealand. Antimicrob. Agents Chemother. 47, 204-210.

Marner, E.S., Wolk, D.M., Carr, J., Hewitt, C., Dominguez, L.L., Kovacs, T., Johnson, D.R., Hayden, R.T., 2011. Diagnostic accuracy of the Cepheid GeneXpert vanA/vanB assay ver. 1.0 to detect the vanA and vanB vancomycin resistance genes in Enterococcus from perianal specimens. Diagn. Microbiol. Infect. Dis. 69, 382-389.

Marshall, C.G., Broadhead, G., Leskiw, B.K., Wright, G.D., 1997. D-Ala-D-Ala ligases from glycopeptide antibiotic-producing organisms are highly homologous to the enterococcal vancomycin-resistance ligases VanA and VanB. Proc. Natl. Acad. Sci. U.S. A $94,6480-6483$. 
Marshall, C.G., Lessard, I.A., Park, I., Wright, G.D., 1998. Glycopeptide antibiotic resistance genes in glycopeptide-producing organisms. Antimicrob. Agents Chemother. 42, 2215-2220.

Marshall, S.H., Donskey, C.J., Hutton-Thomas, R., Salata, R.A., Rice, L.B., 2002. Gene dosage and linezolid resistance in Enterococcus faecium and Enterococcus faecalis. Antimicrob. Agents Chemother. 46, 3334-3336.

Martel, A., Devriese, L.A., Decostere, A., Haesebrouck, F., 2003. Presence of macrolide resistance genes in streptococci and enterococci isolated from pigs and pork carcasses. Int. J. Food Microbiol. 84, 27-32.

Martone, W.J., 1998. Spread of vancomycin-resistant enterococci: why did it happen in the United States? Infect. Control Hosp. Epidemiol. 19, 539-545.

McBride, S.M., Fischetti, V.A., Leblanc, D.J., Moellering, R.C., Jr., Gilmore, M.S., 2007. Genetic diversity among Enterococcus faecalis. PLoS. ONE. 2, e582-

McDonald, L.C., Kuehnert, M.J., Tenover, F.C., Jarvis, W.R., 1997. Vancomycin-resistant enterococci outside the health-care setting: prevalence, sources, and public health implications. Emerg. Infect. Dis. 3, 311-317.

McKessar, S.J., Berry, A.M., Bell, J.M., Turnidge, J.D., Paton, J.C., 2000. Genetic characterization of vanG, a novel vancomycin resistance locus of Enterococcus faecalis. Antimicrob. Agents Chemother. 44, 3224-3228.

Mevius, D., Devriese, L., Butaye, P., Vandamme, P., Verschure, M., Veldman, K., 1998. Isolation of glycopeptide resistant Streptococcus gallolyticus strains with vanA, vanB, and both vanA and vanB genotypes from faecal samples of veal calves in The Netherlands. J. Antimicrob. Chemother. 42, 275-276.

Meziane-Cherif, D., Saul, F.A., Moubareck, C., Weber, P., Haouz, A., Courvalin, P., Perichon, B., 2010. Molecular basis of vancomycin dependence in VanA-type Staphylococcus aureus VRSA-9. J. Bacteriol. 192, 5465-5471.

Min, Y.H., Kwon, A.R., Yoon, J.M., Yoon, E.J., Shim, M.J., Choi, E.C., 2008. Molecular analysis of constitutive mutations in ermB and ermA selected in vitro from inducibly MLSB-resistant enterococci. Arch. Pharm. Res. 31, 377-380.

Moore, I.F., Hughes, D.W., Wright, G.D., 2005. Tigecycline is modified by the flavindependent monooxygenase TetX. Biochemistry 44, 11829-11835.

Morris-Downes, M., Smyth, E.G., Moore, J., Thomas, T., Fitzpatrick, F., Walsh, J., Caffrey, V., Morris, A., Foley, S., Humphreys, H., 2010. Surveillance and endemic vancomycinresistant enterococci: some success in control is possible. J. Hosp. Infect. 75, 228-233.

Moubareck, C., Bourgeois, N., Courvalin, P., Doucet-Populaire, F., 2003. Multiple antibiotic resistance gene transfer from animal to human enterococci in the digestive tract of gnotobiotic mice. Antimicrob. Agents Chemother. 47, 2993-2996.

Moubareck, C., Meziane-Cherif, D., Courvalin, P., Perichon, B., 2009. VanA-type Staphylococcus aureus strain VRSA-7 is partially dependent on vancomycin for growth. Antimicrob. Agents Chemother. 53, 3657-3663.

Murray, B.E., 1990. The life and times of the Enterococcus. Clin. Microbiol. Rev. 3, 46-65.

Murray, B.E., 2000. Vancomycin-resistant enterococcal infections. N. Engl. J. Med. 342, 710721.

Nallapareddy, S.R., Singh, K.V., Okhuysen, P.C., Murray, B.E., 2008. A functional collagen adhesin gene, acm, in clinical isolates of Enterococcus faecium correlates with the recent success of this emerging nosocomial pathogen. Infect. Immun. 76, 4110-4119. 
Nallapareddy, S.R., Wenxiang, H., Weinstock, G.M., Murray, B.E., 2005. Molecular characterization of a widespread, pathogenic, and antibiotic resistance-receptive Enterococcus faecalis lineage and dissemination of its putative pathogenicity island. J. Bacteriol. 187, 5709-5718.

Nannini, E., Murray, B.E., Arias, C.A., 2010. Resistance or decreased susceptibility to glycopeptides, daptomycin, and linezolid in methicillin-resistant Staphylococcus aureus. Curr. Opin. Pharmacol. 10, 516-521.

Naser, S.M., Vancanneyt, M., Hoste, B., Snauwaert, C., Vandemeulebroecke, K., Swings, J., 2006b. Reclassification of Enterococcus flavescens Pompei et al. 1992 as a later synonym of Enterococcus casseliflavus (ex Vaughan et al. 1979) Collins et al. 1984 and Enterococcus saccharominimus Vancanneyt et al. 2004 as a later synonym of Enterococcus italicus Fortina et al. 2004. Int. J. Syst. Evol. Microbiol. 56, 413-416.

Naser, S.M., Vancanneyt, M., Hoste, B., Snauwaert, C., Vandemeulebroecke, K., Swings, J., 2006a. Reclassification of Enterococcus flavescens Pompei et al. 1992 as a later synonym of Enterococcus casseliflavus (ex Vaughan et al. 1979) Collins et al. 1984 and Enterococcus saccharominimus Vancanneyt et al. 2004 as a later synonym of Enterococcus italicus Fortina et al. 2004. Int. J. Syst. Evol. Microbiol. 56, 413-416.

Neves, F.P., Ribeiro, R.L., Duarte, R.S., Teixeira, L.M., Merquior, V.L., 2009. Emergence of the vanA genotype among Enterococcus gallinarum isolates colonising the intestinal tract of patients in a university hospital in Rio de Janeiro, Brazil. Int. J. Antimicrob. Agents 33, 211-215.

Nichol, K.A., Sill, M., Laing, N.M., Johnson, J.L., Hoban, D.J., Zhanel, G.G., 2006. Molecular epidemiology of urinary tract isolates of vancomycin-resistant Enterococcus faecium from North America. International Journal of Antimicrobial Agents 27, 392-396.

Nilsson, O., Greko, C., Bengtsson, B., 2009a. Environmental contamination by vancomycin resistant enterococci (VRE) in Swedish broiler production. Acta Vet. Scand. 51, 49-

Nilsson, O., Greko, C., Top, J., Franklin, A., Bengtsson, B., 2009b. Spread without known selective pressure of a vancomycin-resistant clone of Enterococcus faecium among broilers. J. Antimicrob. Chemother. 63, 868-872.

Noble, W.C., Virani, Z., Cree, R.G., 1992. Co-transfer of vancomycin and other resistance genes from Enterococcus faecalis NCTC 12201 to Staphylococcus aureus. FEMS Microbiol. Lett. 72, 195-198.

Novais, C., Freitas, A.R., Sousa, J.C., Baquero, F., Coque, T.M., Peixe, L.V., 2008. Diversity of Tn1546 and its role in the dissemination of vancomycin-resistant enterococci in Portugal. Antimicrob. Agents Chemother. 52, 1001-1008.

Novick, R.P., Murphy, E., 1985. MLS-resistance determinants in Staphylococcus aureus and their molecular evolution. J. Antimicrob. Chemother. 16 Suppl A, 101-110.

Onodera, Y., Okuda, J., Tanaka, M., Sato, K., 2002. Inhibitory activities of quinolones against DNA gyrase and topoisomerase IV of Enterococcus faecalis. Antimicrob. Agents Chemother. 46, 1800-1804.

Oteo, J., Cuevas, O., Navarro, C., Aracil, B., Campos, J., on behalf of the Spanish Group of 'The European Antimicrobial Resistance Surveillance System' (EARSS), 2007. Trends in antimicrobial resistance in 3469 enterococci isolated from blood (EARSS experience 2001-06, Spain): increasing ampicillin resistance in Enterococcus faecium. J. Antimicrob. Chemother. 59, 1044-1045. 
Oyamada, Y., Ito, H., Fujimoto, K., Asada, R., Niga, T., Okamoto, R., Inoue, M., Yamagishi, J.i., 2006a. Combination of known and unknown mechanisms confers high-level resistance to fluoroquinolones in Enterococcus faecium. J Med Microbiol 55, 729736.

Oyamada, Y., Ito, H., Inoue, M., Yamagishi, J.i., 2006b. Topoisomerase mutations and efflux are associated with fluoroquinolone resistance in Enterococcus faecalis. J Med Microbiol 55, 1395-1401.

Padiglione, A.A., Grabsch, E.A., Olden, D., Hellard, M., Sinclair, M.I., Fairley, C.K., Grayson, M.L., 2000. Fecal colonization with vancomycin-resistant enterococci in Australia. Emerg. Infect. Dis. 6, 534-536.

Pai, M.P., Rodvold, K.A., Schreckenberger, P.C., Gonzales, R.D., Petrolatti, J.M., Quinn, J.P., 2002. Risk factors associated with the development of infection with linezolid- and vancomycin-resistant Enterococcus faecium. Clin. Infect. Dis. 35, 1269-1272.

Palmer, K.L., Carniol, K., Manson, J.M., Heiman, D., Shea, T., Young, S., Zeng, Q., Gevers, D., Feldgarden, M., Birren, B., Gilmore, M.S., 2010. High-quality draft genome sequences of 28 Enterococcus sp. isolates. J. Bacteriol. 192, 2469-2470.

Panesso, D., badia-Patino, L., Vanegas, N., Reynolds, P.E., Courvalin, P., Arias, C.A., 2005. Transcriptional analysis of the vanC cluster from Enterococcus gallinarum strains with constitutive and inducible vancomycin resistance. Antimicrob. Agents Chemother. 49, 1060-1066.

Panesso, D., Reyes, J., Rincon, S., Diaz, L., Galloway-Pena, J., Zurita, J., Carrillo, C., Merentes, A., Guzman, M., Adachi, J.A., Murray, B.E., Arias, C.A., 2010. Molecular epidemiology of vancomycin-resistant Enterococcus faecium: a prospective, multicenter study in South American hospitals. J. Clin. Microbiol. 48, 1562-1569.

Park, I.J., Lee, W.G., Lim, Y.A., Cho, S.R., 2007. Genetic rearrangements of Tn1546-like elements in vancomycin-resistant Enterococcus faecium isolates collected from hospitalized patients over a seven-year period. J. Clin. Microbiol. 45, 3903-3908.

Park, I.J., Lee, W.G., Shin, J.H., Lee, K.W., Woo, G.J., 2008. VanB phenotype-vanA genotype Enterococcus faecium with heterogeneous expression of teicoplanin resistance. J. Clin. Microbiol. 46, 3091-3093.

Patel, R., 2000. Enterococcal-type glycopeptide resistance genes in non-enterococcal organisms. FEMS Microbiol. Lett. 185, 1-7.

Patel, R., Piper, K., Cockerill, F.R., III, Steckelberg, J.M., Yousten, A.A., 2000. The biopesticide Paenibacillus popilliae has a vancomycin resistance gene cluster homologous to the enterococcal VanA vancomycin resistance gene cluster. Antimicrob. Agents Chemother. 44, 705-709.

Paulsen, I.T., Banerjei, L., Myers, G.S., Nelson, K.E., Seshadri, R., Read, T.D., Fouts, D.E., Eisen, J.A., Gill, S.R., Heidelberg, J.F., Tettelin, H., Dodson, R.J., Umayam, L., Brinkac, L., Beanan, M., Daugherty, S., DeBoy, R.T., Durkin, S., Kolonay, J., Madupu, R., Nelson, W., Vamathevan, J., Tran, B., Upton, J., Hansen, T., Shetty, J., Khouri, H., Utterback, T., Radune, D., Ketchum, K.A., Dougherty, B.A., Fraser, C.M., 2003. Role of mobile DNA in the evolution of vancomycin-resistant Enterococcus faecalis. Science 299, 2071-2074.

Pearman, J.W., 2006. 2004 Lowbury Lecture: the Western Australian experience with vancomycin-resistant enterococci - from disaster to ongoing control. Journal of Hospital Infection 63, 14-26. 
Pendle, S., Jelfs, P., Olma, T., Su, Y., Gilroy, N., Gilbert, G.L., 2008. Difficulties in detection and identification of Enterococcus faecium with low-level inducible resistance to vancomycin, during a hospital outbreak. Clin. Microbiol. Infect. 14, 853-857.

Perichon, B., Courvalin, P., 2004. Heterologous expression of the enterococcal vanA operon in methicillin-resistant Staphylococcus aureus. Antimicrob. Agents Chemother. 48, 4281-4285.

Perichon, B., Courvalin, P., 2006. Synergism between beta-lactams and glycopeptides against VanA-type Methicillin-Resistant Staphylococcus aureus and heterologous expression of the vanA operon. Antimicrob. Agents Chemother. 50, 3622-3630.

Poole, T.L., Hume, M.E., Campbell, L.D., Scott, H.M., Alali, W.Q., Harvey, R.B., 2005. Vancomycin-resistant Enterococcus faecium strains isolated from community wastewater from a semiclosed agri-food system in Texas. Antimicrob. Agents Chemother. 49, 4382-4385.

Poyart, C., Pierre, C., Quesne, G., Pron, B., Berche, P., Trieu-Cuot, P., 1997. Emergence of vancomycin resistance in the genus Streptococcus: characterization of a vanB transferable determinant in Streptococcus bovis. Antimicrob. Agents Chemother. 41, 24-29.

Prystowsky, J., Siddiqui, F., Chosay, J., Shinabarger, D.L., Millichap, J., Peterson, L.R., Noskin, G.A., 2001. Resistance to linezolid: characterization of mutations in rRNA and comparison of their occurrences in vancomycin-resistant enterococci. Antimicrob. Agents Chemother. 45, 2154-2156.

Qi, C., Zheng, X., Obias, A., Scheetz, M.H., Malczynski, M., Warren, J.R., 2006. Comparison of testing methods for detection of decreased linezolid susceptibility due to G2576T mutation of the 23S rRNA gene in Enterococcus faecium and Enterococcus faecalis. J. Clin. Microbiol. 44, 1098-1100.

Quinones Perez, D., 2006. Epidemiology of antimicrobial resistance in Enterococcus spp. from Cuba and other Latin American countries. In: Kobayashi, N. (Eds), Drug resistance of enterococci: Epidemiology and molecular mechanisms. Research Signpost, Kerala, India, pp. 1-20.

Rahim, S., Pillai, S.K., Gold, H.S., Venkataraman, L., Inglima, K., Press, R.A., 2003. Linezolidresistant, vancomycin-resistant Enterococcus faecium infection in patients without prior exposure to linezolid. Clin. Infect. Dis. 36, E146-E148.

Ramsey, A.M., Zilberberg, M.D., 2009. Secular trends of hospitalization with vancomycinresistant enterococcus infection in the United States, 2000-2006. Infect. Control Hosp. Epidemiol. 30, 184-186.

Reynolds, E., Cove, J.H., 2005. Enhanced resistance to erythromycin is conferred by the enterococcal msrC determinant in Staphylococcus aureus. J. Antimicrob. Chemother. 55, 260-264.

Reynolds, E., Ross, J.I., Cove, J.H., 2003. Msr(A) and related macrolide/streptogramin resistance determinants: incomplete transporters? Int. J. Antimicrob. Agents 22, 228-236.

Reynolds, P.E., Arias, C.A., Courvalin, P., 1999. Gene vanXYC encodes D,D -dipeptidase (VanX) and D,D-carboxypeptidase (VanY) activities in vancomycin-resistant Enterococcus gallinarum BM4174. Mol. Microbiol. 34, 341-349.

Reynolds, P.E., Courvalin, P., 2005. Vancomycin resistance in enterococci due to synthesis of precursors terminating in D-alanyl-D-serine. Antimicrob. Agents Chemother. 49, $21-25$. 
Rice, L.B., 2006. Antimicrobial resistance in gram-positive bacteria. Am. J. Infect. Control 34, S11-S19.

Rice, L.B., Carias, L.L., Donskey, C.L., Rudin, S.D., 1998. Transferable, plasmid-mediated vanB-type glycopeptide resistance in Enterococcus faecium. Antimicrob. Agents Chemother. 42, 963-964.

Rice, L.B., Carias, L.L., Marshall, S., Rudin, S.D., Hutton-Thomas, R., 2005. Tn5386, a novel Tn916-like mobile element in Enterococcus faecium D344R that interacts with Tn916 to yield a large genomic deletion. J. Bacteriol. 187, 6668-6677.

Rice, L.B., Carias, L.L., Marshall, S.H., Hutton-Thomas, R., Rudin, S., 2007. Characterization of Tn5386, a Tn916-related mobile element. Plasmid 58, 61-67.

Rice, L.B., Carias, L.L., Rudin, S., Hutton, R., Marshall, S., Hassan, M., Josseaume, N., Dubost, L., Marie, A., Arthur, M., 2009. Role of class A penicillin-binding proteins in the expression of beta-lactam resistance in Enterococcus faecium. J. Bacteriol. 191, 3649-3656.

Rice, L.B., Carias, L.L., Rudin, S., Hutton, R.A., Marshall, S., 2010. Multiple copies of functional, Tet(M)-encoding Tn916-like elements in a clinical Enterococcus faecium isolate. Plasmid

Rice, L.B., Bellais, S., Carias, L.L., Hutton-Thomas, R., Bonomo, R.A., Caspers, P., Page, M.G.P., Gutmann, L., 2004. Impact of specific pbp5 mutations on expression of \{beta\}-lactam resistance in Enterococcus faecium. Antimicrob. Agents Chemother. 48, 3028-3032.

Roberts, A.P., Johanesen, P.A., Lyras, D., Mullany, P., Rood, J.I., 2001. Comparison of Tn5397 from Clostridium difficile, Tn916 from Enterococcus faecalis and the CW459tet(M) element from Clostridium perfringens shows that they have similar conjugation regions but different insertion and excision modules. Microbiology 147, 1243-1251.

Roberts, A.P., Mullany, P., 2009. A modular master on the move: the Tn916 family of mobile genetic elements. Trends Microbiol. 17, 251-258.

Roberts, A.P., Mullany, P., 2011. Tn916-like genetic elements: a diverse group of modular mobile elements conferring antibiotic resistance. FEMS Microbiol. Rev.

Roberts, M.C., 2005. Update on acquired tetracycline resistance genes. FEMS Microbiol. Lett. 245, 195-203.

Roberts, M.C., Sutcliffe, J., Courvalin, P., Jensen, L.B., Rood, J., Seppala, H., 1999. Nomenclature for macrolide and macrolide-lincosamide-streptogramin B resistance determinants. Antimicrob. Agents Chemother. 43, 2823-2830.

Rodriguez-Martinez, J.M., Velasco, C., Briales, A., Garcia, I., Conejo, M.C., Pascual, A., 2008. Qnr-like pentapeptide repeat proteins in gram-positive bacteria. J. Antimicrob. Chemother. 61, 1240-1243.

Rosato, A., Pierre, J., Billot-Klein, D., Buu-Hoi, A., Gutmann, L., 1995. Inducible and constitutive expression of resistance to glycopeptides and vancomycin dependence in glycopeptide-resistant Enterococcus avium. Antimicrob. Agents Chemother. 39, 830-833.

Rosato, A., Vicarini, H., Leclercq, R., 1999. Inducible or constitutive expression of resistance in clinical isolates of streptococci and enterococci cross-resistant to erythromycin and lincomycin. J. Antimicrob. Chemother. 43, 559-562.

Rosvoll, T.C.S., Pedersen, T., Sletvold, H., Johnsen, P.J., Sollid, J.E., Simonsen, G.S., Jensen, L.B., Nielsen, K.M., Sundsfjord, A., 2009. PCR-based plasmid typing in Enterococcus faecium strains reveals widely distributed pRE25-, pRUM-, pIP501- 
and pHTbeta-related replicons associated with glycopeptide resistance and stabilizing toxin-antitoxin systems. FEMS Immunology and Medical Microbiology 58, 254-268.

Ruggero, K.A., Schroeder, L.K., Schreckenberger, P.C., Mankin, A.S., Quinn, J.P., 2003. Nosocomial superinfections due to linezolid-resistant Enterococcus faecalis: evidence for a gene dosage effect on linezolid MICs. Diagn. Microbiol. Infect. Dis. 47, 511-513.

Ruiz-Garbajosa, P., Bonten, M.J., Robinson, D.A., Top, J., Nallapareddy, S.R., Torres, C., Coque, T.M., Canton, R., Baquero, F., Murray, B.E., Del, C.R., Willems, R.J., 2006. Multilocus sequence typing scheme for Enterococcus faecalis reveals hospitaladapted genetic complexes in a background of high rates of recombination. J. Clin. Microbiol. 44, 2220-2228.

Sader, H.S., Moet, G.J., Jones, R.N., 2009. Antimicrobial resistance among Gram-positive bacteria isolated in Latin American hospitals. J. Chemother. 21, 611-620.

Saeedi, B., Hallgren, A., Isaksson, B., Jonasson, J., Nilsson, L.E., Hanberger, H., 2004. Genetic relatedness of Enterococcus faecalis isolates with high-level gentamicin resistance from patients with bacteraemia in the south east of Sweden 1994-2001. Scand. J. Infect. Dis. 36, 405-409.

Sahlstrom, L., Rehbinder, V., Albihn, A., Aspan, A., Bengtsson, B., 2009. Vancomycin resistant enterococci (VRE) in Swedish sewage sludge. Acta Vet. Scand. 51, 24-

Sahm, D.F., Kissinger, J., Gilmore, M.S., Murray, P.R., Mulder, R., Solliday, J., Clarke, B., 1989. In vitro susceptibility studies of vancomycin-resistant Enterococcus faecalis. Antimicrob. Agents Chemother. 33, 1588-1591.

San Millan, A., Depardieu, F., Godreuil, S., Courvalin, P., 2009a. VanB-type Enterococcus faecium clinical isolate successively inducibly resistant to, dependent on, and constitutively resistant to vancomycin. Antimicrob. Agents Chemother. 53, 1974-1982.

San Millan, A., Depardieu, F., Godreuil, S., Courvalin, P., 2009b. VanB-type Enterococcus faecium clinical isolate successively inducibly resistant to, dependent on, and constitutively resistant to vancomycin. Antimicrob. Agents Chemother. 53, 1974-1982.

Schmitz, F.J., Witte, W., Werner, G., Petridou, J., Fluit, A.C., Schwarz, S., 2001. Characterization of the translational attenuator of 20 methicillin-resistant, quinupristin/dalfopristin-resistant Staphylococcus aureus isolates with reduced susceptibility to glycopeptides. J. Antimicrob. Chemother. 48, 939-941.

Schouten, M.A., Voss, A., Hoogkamp-Korstanje, J.A., 1997. VRE and meat. Lancet 349, 1258-

Schwarz, F.V., Perreten, V., Teuber, M., 2001. Sequence of the 50-kb conjugative multiresistance plasmid pRE25 from Enterococcus faecalis RE25. Plasmid 46, 170-187.

Sebaihia, M., Wren, B.W., Mullany, P., Fairweather, N.F., Minton, N., Stabler, R., Thomson, N.R., Roberts, A.P., Cerdeno-Tarraga, A.M., Wang, H., Holden, M.T., Wright, A., Churcher, C., Quail, M.A., Baker, S., Bason, N., Brooks, K., Chillingworth, T., Cronin, A., Davis, P., Dowd, L., Fraser, A., Feltwell, T., Hance, Z., Holroyd, S., Jagels, K., Moule, S., Mungall, K., Price, C., Rabbinowitsch, E., Sharp, S., Simmonds, M., Stevens, K., Unwin, L., Whithead, S., Dupuy, B., Dougan, G., Barrell, B., Parkhill, J., 2006. The multidrug-resistant human pathogen Clostridium difficile has a highly mobile, mosaic genome. Nat. Genet. 38, 779-786.

Seedat, J., Zick, G., Klare, I., Konstabel, C., Weiler, N., Sahly, H., 2006. Rapid emergence of resistance to linezolid during linezolid therapy of an Enterococcus faecium infection. Antimicrob. Agents Chemother. 50, 4217-4219. 
Shaw, J.H., Clewell, D.B., 1985. Complete nucleotide sequence of macrolide-lincosamidestreptogramin B-resistance transposon Tn917 in Streptococcus faecalis. J. Bacteriol. 164, 782-796.

Shin, E., Hong, H., Ike, Y., Lee, K., Park, Y.H., Cho, D.T., Lee, Y., 2006. VanB-vanA incongruent VRE isolated from animals and humans in 1999. J. Microbiol. 44, 453-456.

Shirano, M., Takakura, S., Yamamoto, M., Matsumura, Y., Matsushima, A., Nagao, M., Fujihara, N., Saito, T., Ito, Y., Iinuma, Y., Shimizu, T., Fujita, N., Ichiyama, S., 2010. Regional spread of vanA- or vanB-positive Enterococcus gallinarum in hospitals and long-term care facilities in Kyoto prefecture, Japan. Epidemiol. Infect. 1-7.

Sievert, D.M., Rudrik, J.T., Patel, J.B., McDonald, L.C., Wilkins, M.J., Hageman, J.C., 2008. Vancomycin-resistant Staphylococcus aureus in the United States, 2002-2006. Clin. Infect. Dis. 46, 668-674.

Sifaoui, F., Gutmann, L., 1997. Vancomycin dependence in a vanA-producing Enterococcus avium strain with a nonsense mutation in the natural D-Ala-D-Ala ligase gene. Antimicrob. Agents Chemother. 41, 1409-

Sillanpaa, J., Nallapareddy, S.R., Prakash, V.P., Qin, X., Hook, M., Weinstock, G.M., Murray, B.E., 2008. Identification and phenotypic characterization of a second collagen adhesin, $\mathrm{Scm}$, and genome-based identification and analysis of 13 other predicted MSCRAMMs, including four distinct pilus loci, in Enterococcus faecium. Microbiology 154, 3199-3211.

Simjee, S., White, D.G., Wagner, D.D., Meng, J., Qaiyumi, S., Zhao, S., McDermott, P.F., 2002. Identification of vat(E) in Enterococcus faecalis isolates from retail poultry and its transferability to Enterococcus faecium. Antimicrob. Agents Chemother. 46, 38233828 .

Simonsen, G.S., Haaheim, H., Dahl, K.H., Kruse, H., Lovseth, A., Olsvik, O., Sundsfjord, A., 1998. Transmission of VanA-type vancomycin-resistant enterococci and vanA resistance elements between chicken and humans at avoparcin-exposed farms. Microb. Drug Resist. 4, 313-318.

Sinclair, A., Arnold, C., Woodford, N., 2003. Rapid detection and estimation by pyrosequencing of $23 \mathrm{~S}$ rRNA genes with a single nucleotide polymorphism conferring linezolid resistance in Enterococci. Antimicrob. Agents Chemother. 47, 3620-3622.

Singh, K.V., Malathum, K., Murray, B.E., 2001. Disruption of an Enterococcus faecium species-specific gene, a homologue of acquired macrolide resistance genes of staphylococci, is associated with an increase in macrolide susceptibility. Antimicrob. Agents Chemother. 45, 263-266.

Singh, K.V., Murray, B.E., 2005. Differences in the Enterococcus faecalis 1sa locus that influence susceptibility to quinupristin-dalfopristin and clindamycin. Antimicrob. Agents Chemother. 49, 32-39.

Singh, K.V., Weinstock, G.M., Murray, B.E., 2002. An Enterococcus faecalis ABC homologue (Lsa) is required for the resistance of this species to clindamycin and quinupristindalfopristin. Antimicrob. Agents Chemother. 46, 1845-1850.

Sivertsen, A., Lundblad, E.W., Wisell, K.T., Liljequist, B., Billström, H., Ullberg, M., Heimer, D., Sjögren, I., Aasnaes, B., Sundsfjord, A., Hegstad, K., 2011. The widespread VRE outbreak in Swedish hospitals 2007-2009 was associated with clonal E. faecium CC17 genogroup strains harbouring several virulence traits and transferable vanB 
pRUM-like repA plasmids. Final Programme of the 21st ECCMID, Milano, May 710, 2011 Poster P924, 113-

Sletvold, H., Johnsen, P.J., Hamre, I., Simonsen, G.S., Sundsfjord, A., Nielsen, K.M., 2008. Complete sequence of Enterococcus faecium pVEF3 and the detection of an omegaepsilon-zeta toxin-antitoxin module and an ABC transporter. Plasmid 60, 75-85.

Sletvold, H., Johnsen, P.J., Simonsen, G.S., Aasnaes, B., Sundsfjord, A., Nielsen, K.M., 2007. Comparative DNA analysis of two vanA plasmids from Enterococcus faecium strains isolated from poultry and a poultry farmer in Norway. Antimicrob. Agents Chemother. 51, 736-739.

Sletvold, H., Johnsen, P.J., Wikmark, O.G., Simonsen, G.S., Sundsfjord, A., Nielsen, K.M., 2010. Tn1546 is part of a larger plasmid-encoded genetic unit horizontally disseminated among clonal Enterococcus faecium lineages. J. Antimicrob. Chemother. 65, 1894-1906.

Sng, L.H., Cornish, N., Knapp, C.C., Ludwig, M.D., Hall, G.S., Washington, J.A., 1998a. Antimicrobial susceptibility testing of a clinical isolate of vancomycin-dependent enterococcus using D-alanine-D-alanine as a growth supplement. Am. J. Clin. Pathol. 109, 399-403.

Sng, L.H., Cornish, N., Knapp, C.C., Ludwig, M.D., Hall, G.S., Washington, J.A., 1998b. Antimicrobial susceptibility testing of a clinical isolate of vancomycin-dependent enterococcus using D-alanine-D-alanine as a growth supplement. Am. J. Clin. Pathol. 109, 399-403.

Soderblom, T., Aspevall, O., Erntell, M., Hedin, G., Heimer, D., Hokeberg, I., KiddLjunggren, K., Melhus, A., Olsson-Liljequist, B., Sjogren, I., Smedjegard, J., Struwe, J., Sylvan, S., Tegmark-Wisell, K., Thore, M., 2010. Alarming spread of vancomycin resistant enterococci in Sweden since 2007. Euro. Surveill 15, pii: 19620.

Sorum, M., Johnsen, P.J., Aasnes, B., Rosvoll, T., Kruse, H., Sundsfjord, A., Simonsen, G.S., 2006. Prevalence, persistence, and molecular characterization of glycopeptideresistant enterococci in Norwegian poultry and poultry farmers 3 to 8 years after the ban on avoparcin. Appl. Environ. Microbiol. 72, 516-521.

Stamper, P.D., Shulder, S., Bekalo, P., Manandhar, D., Ross, T.L., Speser, S., Kingery, J., Carroll, K.C., 2010. Evaluation of BBL CHROMagar VanRE for detection of vancomycinresistant Enterococci in rectal swab specimens. J. Clin. Microbiol. 48, 4294-4297.

Stamper, P.D., Cai, M., Lema, C., Eskey, K., Carroll, K.C., 2007. Comparison of the BD GeneOhm VanR Assay to culture for identification of vancomycin-resistant enterococci in rectal and stool specimens. J. Clin. Microbiol. 45, 3360-3365.

Stinear, T.P., Olden, D.C., Johnson, P.D., Davies, J.K., Grayson, M.L., 2001. Enterococcal vanB resistance locus in anaerobic bacteria in human faeces. The Lancet 357, 855-856.

Stobberingh, E., van Den, B.A., London, N., Driessen, C., Top, J., Willems, R., 1999. Enterococci with glycopeptide resistance in turkeys, turkey farmers, turkey slaughterers, and (sub)urban residents in the south of The Netherlands: evidence for transmission of vancomycin resistance from animals to humans? Antimicrob. Agents Chemother. 43, 2215-2221.

Straus, S.K., Hancock, R.E., 2006a. Mode of action of the new antibiotic for Gram-positive pathogens daptomycin: comparison with cationic antimicrobial peptides and lipopeptides. Biochim. Biophys. Acta 1758, 1215-1223. 
Straus, S.K., Hancock, R.E., 2006b. Mode of action of the new antibiotic for Gram-positive pathogens daptomycin: comparison with cationic antimicrobial peptides and lipopeptides. Biochim. Biophys. Acta 1758, 1215-1223.

Tanimoto, K., Nomura, T., Maruyama, H., Tomita, H., Shibata, N., Arakawa, Y., Ike, Y., 2006. First VanD-Type vancomycin-resistant Enterococcus raffinosus isolate. Antimicrob. Agents Chemother. 50, 3966-3967.

Tenover, F.C., McDonald, L.C., 2005. Vancomycin-resistant staphylococci and enterococci: epidemiology and control. Curr. Opin. Infect. Dis. 18, 300-305.

Teuber, M., Schwarz, F., Perreten, V., 2003. Molecular structure and evolution of the conjugative multiresistance plasmid pRE25 of Enterococcus faecalis isolated from a raw-fermented sausage. International Journal of Food Microbiology 88, 325-329.

Thal, L.A., Silverman, J., Donabedian, S., Zervos, M.J., 1997. The effect of Tn916 insertions on contour-clamped homogeneous electrophoresis patterns of Enterococcus faecalis. J. Clin. Microbiol. 35, 969-972.

Toh, S.M., Xiong, L., Arias, C.A., Villegas, M.V., Lolans, K., Quinn, J., Mankin, A.S., 2007. Acquisition of a natural resistance gene renders a clinical strain of methicillinresistant Staphylococcus aureus resistant to the synthetic antibiotic linezolid. Molecular Microbiology 64, 1506-1514.

Top, J., Willems, R., Blok, H., de Regt, M., Jalink, K., Troelstra, A., Goorhuis, B., Bonten, M., 2007. Ecological replacement of Enterococcus faecalis by multiresistant clonal complex 17 Enterococcus faecium. Clinical Microbiology and Infection 13, 316-319.

Top, J., Willems, R., Bonten, M., 2008a. Emergence of CC17 Enterococcus faecium: from commensal to hospital-adapted pathogen. FEMS Immunol. Med. Microbiol. 52, 297-308.

Top, J., Willems, R., van, d., V, Asbroek, M., Bonten, M., 2008b. Emergence of clonal complex 17 Enterococcus faecium in The Netherlands. J. Clin. Microbiol. 46, 214-219.

Torres, C., Reguera, J.A., Sanmartin, M.J., Perez-Diaz, J.C., Baquero, F., 1994. vanA-mediated vancomycin-resistant Enterococcus spp. in sewage. J. Antimicrob. Chemother. 33, 553-561.

Tsvetkova, K., Marvaud, J.C., Lambert, T., 2010. Analysis of the mobilization functions of the vancomycin resistance transposon Tn1549, a member of a new family of conjugative elements. J. Bacteriol. 192, 702-713.

Usacheva, E.A., Ginocchio, C.C., Morgan, M., Maglanoc, G., Mehta, M.S., Tremblay, S., Karchmer, T.B., Peterson, L.R., 2010. Prospective, multicenter evaluation of the BD GeneOhm VanR assay for direct, rapid detection of vancomycin-resistant Enterococcus species in perianal and rectal specimens. Am. J. Clin. Pathol. 134, 219226.

Valdezate, S., Labayru, C., Navarro, A., Mantecon, M.A., Ortega, M., Coque, T.M., Garcia, M., Saez-Nieto, J.A., 2009. Large clonal outbreak of multidrug-resistant CC17 ST17 Enterococcus faecium containing Tn5382 in a Spanish hospital. J. Antimicrob. Chemother. 63, 17-20.

Van Caeseele, P., Giercke, S., Wylie, J., Boyd, D., Mulvey, M., Amin, S., Ofner-Agostini, M., 2001. Identification of the first vancomycin-resistant Enterococcus faecalis harbouring vanE in Canada. Can. Commun. Dis. Rep. 27, 101-104.

Van Den Bogaard, A.E., Mertens, P., London, N.H., Stobberingh, E.E., 1997. High prevalence of colonization with vancomycin- and pristinamycin-resistant enterococci in 
healthy humans and pigs in The Netherlands: is the addition of antibiotics to animal feeds to blame? J. Antimicrob. Chemother. 40, 454-456.

van den Braak, N., van Belkum, A., van Keulen, M., Vliegenthart, J., Verbrugh, H.A., Endtz, H.P., 1998. Molecular characterization of vancomycin-resistant enterococci from hospitalized patients and poultry products in The Netherlands. J. Clin. Microbiol. 36, 1927-1932.

van Schaik, W., Top, J., Riley, D.R., Boekhorst, J., Vrijenhoek, J.E.P.V., Schapendonk, C.M.E., Hendrickx, A.P.A., Nijman, I.J., Bonten, M.J.M., Tettelin, H., Willems, R.J.L., 2010. Pyrosequencing-based comparative genome analysis of the nosocomial pathogen Enterococcus faecium and identification of a large transferable pathogenicity island. BMC Genomics 11, 239-

van Schaik, W., Willems, R.J., 2010. Genome-based insights into the evolution of enterococci. Clin. Microbiol. Infect.

Weaver, K.E., Kwong, S.M., Firth, N., Francia, M.V., 2009. The RepA_N replicons of Grampositive bacteria: a family of broadly distributed but narrow host range plasmids. Plasmid 61, 94-109.

Weber, P., Meziane-Cherif, D., Haouz, A., Saul, F.A., Courvalin, P., 2009. Crystallization and preliminary X-ray analysis of a D-Ala:D-Ser ligase associated with VanG-type vancomycin resistance. Acta Crystallogr. Sect. F. Struct. Biol. Cryst. Commun. 65, 1024-1026.

Weigel, L.M., Clewell, D.B., Gill, S.R., Clark, N.C., McDougal, L.K., Flannagan, S.E., Kolonay, J.F., Shetty, J., Killgore, G.E., Tenover, F.C., 2003. Genetic analysis of a high-level vancomycin-resistant isolate of Staphylococcus aureus. Science 302, 1569-1571.

Werckenthin, C., Schwarz, S., 2000. Molecular analysis of the translational attenuator of a constitutively expressed erm(A) gene from Staphylococcus intermedius. J. Antimicrob. Chemother. 46, 785-788.

Werckenthin, C., Schwarz, S., Westh, H., 1999. Structural alterations in the translational attenuator of constitutively expressed ermC genes. Antimicrob. Agents Chemother. 43, 1681-1685.

Werner, G., 2011. Surveillance of antimicrobial resistance among Enterococcus faecium and Enterococcus faecalis isolated from human (clinical/commensal), food animal, meat and environmental samples. In: Semedo-Lemsaddek, T., Barreto-Crespo, M.T., Tenreiro, R. (Eds), Enterococcus and safety. Nova Science Publishers Inc., Hauppage, N.Y., pp. [in press]-.

Werner, G., Bartel, M., Wellinghausen, N., Essig, A., Klare, I., Witte, W., Poppert, S., 2007a. Detection of mutations conferring resistance to linezolid in Enterococcus spp. by fluorescence in situ hybridization. J. Clin. Microbiol. 45, 3421-3423.

Werner, G., Coque, T.M., Hammerum, A.M., Hope, R., Hryniewicz, W., Johnson, A., Klare, I., Kristinsson, K.G., Leclercq, R., Lester, C.H., Lillie, M., Novais, C., OlssonLiljequist, B., Peixe, L.V., Sadowy, E., Simonsen, G.S., Top, J., Vuopio-Varkila, J., Willems, R.J., Witte, W., Woodford, N., 2008a. Emergence and spread of vancomycin resistance among enterococci in Europe. Euro. Surveill 13, pii: 19046-

Werner, G., Dahl, K.H., Willems, R.J., 2006. Composite elements encoding antibiotic resistance in Enterococcus faecium and Enterococcus faecalis. In: Kobayashi, N. (Eds), Drug Resistance in Enterococci: Epidemiology and Molecular Markers. Research Signpost, Fort P.O., Trivandrum, Kerala, pp. 157-208. 
Werner, G., Fleige, C., Ewert, B., Laverde-Gomez, J.A., Klare, I., Witte, W., 2010a. High-level ciprofloxacin resistance among hospital-adapted Enterococcus faecium (CC17). Int. J. Antimicrob. Agents 35, 119-125.

Werner, G., Fleige, C., Geringer, U., van, S.W., Klare, I., Witte, W., 2011a. IS element IS16 as a molecular screening tool to identify hospital-associated strains of Enterococcus faecium. BMC. Infect. Dis. 11, 80-

Werner, G., Freitas, A.R., Coque, T.M., Sollid, J.E., Lester, C., Hammerum, A.M., GarciaMigura, L., Jensen, L.B., Francia, M.V., Witte, W., Willems, R.J., Sundsfjord, A., $2010 \mathrm{~b}$. Host range of enterococcal vanA plasmids among Gram-positive intestinal bacteria. J. Antimicrob. Chemother.

Werner, G., Freitas, A.R., Coque, T.M., Sollid, J.E., Lester, C., Hammerum, A.M., GarciaMigura, L., Jensen, L.B., Francia, M.V., Witte, W., Willems, R.J., Sundsfjord, A., 2011b. Host range of enterococcal vanA plasmids among Gram-positive intestinal bacteria. J. Antimicrob. Chemother. 66, 273-282.

Werner, G., Gfrörer, S., Fleige, C., Witte, W., Klare, I., 2008b. Tigecycline-resistant Enterococcus faecalis strain isolated from a German ICU patient. J. Antimicrob. Chemother. 61, 1182-1183.

Werner, G., Hildebrandt, B., Witte, W., 2001a. Aminoglycoside-streptothricin resistance gene cluster aadE-sat4-aphA-3 disseminated among multiresistant isolates of Enterococcus faecium. Antimicrob. Agents Chemother. 45, 3267-3269.

Werner, G., Hildebrandt, B., Witte, W., 2001b. The newly described msrC gene is not equally distributed among all isolates of Enterococcus faecium. Antimicrob. Agents Chemother. 45, 3672-3673.

Werner, G., Hildebrandt, B., Witte, W., 2003a. Linkage of erm(B) and aadE-sat4-aphA-3 in multiple-resistant Enterococcus faecium isolates of different ecological origins. Microb. Drug Resist. 9 Suppl 1, S9-16.

Werner, G., Klare, I., Heier, H., Hinz, K.H., Bohme, G., Wendt, M., Witte, W., 2000. Quinupristin/dalfopristin-resistant enterococci of the satA (vatD) and satG (vatE) genotypes from different ecological origins in Germany. Microb. Drug Resist. 6, 3747.

Werner, G., Klare, I., Konstabel, C., Witte, W., 2007b. The current MLVA typing scheme for Enterococcus faecium does not discriminate enough to resolve epidemic-virulent, hospital-adapted clonal types. BMC Microbiology 7, 28-

Werner, G., Klare, I., Spencker, F.B., Witte, W., 2003b. Intra-hospital dissemination of quinupristin/dalfopristin- and vancomycin-resistant Enterococcus faecium in a paediatric ward of a German hospital. J. Antimicrob. Chemother. 52, 113-115.

Werner, G., Klare, I., Witte, W., 1997. Arrangement of the vanA gene cluster in enterococci of different ecological origin. FEMS Microbiol. Lett. 155, 55-61.

Werner, G., Klare, I., Witte, W., 2002. Molecular analysis of streptogramin resistance in enterococci. Int. J. Med. Microbiol. 292, 81-94.

Werner, G., Serr, A., Schütt, S., Schneider, C., Klare, I., Witte, W., Wendt, C., 2011c. Comparison of direct cultivation on a selective solid medium, polymerase chain reaction from an enrichment broth, and the $\mathrm{BD}$ GeneOhm ${ }^{\mathrm{TM}}$ VanR Assay for identification of vancomycin-resistant enterococci in screening specimens. Diagnostic Microbiology and Infectious Diseases 70, 512-521.

Werner, G., Strommenger, B., Witte, W., 2008c. Acquired vancomycin resistance in clinically relevant pathogens. Future Microbiology 3, 547-562. 
Werner, G., Klare, I., Fleige, C., Witte, W., 2007c. Increasing rates of vancomycin resistance among Enterococcus faecium isolated from German hospitals between 2004 and 2006 are due to wide clonal dissemination of vancomycin-resistant enterococci and horizontal spread of vanA clusters. International Journal of Medical Microbiology 298, 515-527.

Werner, G., Strommenger, B., Klare, I., Witte, W., 2004. Molecular detection of linezolid resistance in Enterococcus faecium and Enterococcus faecalis by use of 5' nuclease real-time PCR compared to a modified classical approach. J. Clin. Microbiol. 42, 5327-5331.

Willems, R.J., Hanage, W.P., Bessen, D.E., Feil, E.J., 2011. Population biology of Grampositive pathogens: high-risk clones for dissemination of antibiotic resistance. FEMS Microbiol. Rev.

Willems, R.J., Homan, W., Top, J., van Santen-Verheuvel, M., Tribe, D., Manzioros, X., Gaillard, C., Vandenbroucke-Grauls, C.M., Mascini, E.M., van, K.E., Van Embden, J.D., Bonten, M.J., 2001. Variant esp gene as a marker of a distinct genetic lineage of vancomycinresistant Enterococcus faecium spreading in hospitals. Lancet 357, 853-855.

Willems, R.J., Top, J., van Den, B.N., van, B.A., Mevius, D.J., Hendriks, G., van SantenVerheuvel, M., Van Embden, J.D., 1999. Molecular diversity and evolutionary relationships of Tn1546-like elements in enterococci from humans and animals. Antimicrob. Agents Chemother. 43, 483-491.

Willems, R.J., van Schaik W., 2009. Transition of Enterococcus faecium from commensal organism to nosocomial pathogen. Future. Microbiol. 4, 1125-1135.

Willems, R.J., Top, J., Smith, D.J., Roper, D.I., North, S.E., Woodford, N., 2003. Mutations in the DNA mismatch repair proteins MutS and MutL of oxazolidinone-resistant or susceptible Enterococcus faecium. Antimicrob. Agents Chemother. 47, 3061-3066.

Willems, R.J., Bonten, M.J., 2007. Glycopeptide-resistant enterococci: deciphering virulence, resistance and epidemicity. Current Opinion in Infectious Diseases 20, 384-390.

Woodford, N., Adebiyi, A.M., Palepou, M.F., Cookson, B.D., 1998. Diversity of VanA glycopeptide resistance elements in enterococci from humans and nonhuman sources. Antimicrob. Agents Chemother. 42, 502-508.

Woodford, N., Johnson, A.P., Morrison, D., Hastings, J.G., Elliott, T.S., Worthington, A., Stephenson, J.R., Chin, A.T., Tolley, J.L., 1994. Vancomycin-dependent enterococci in the United Kingdom. J. Antimicrob. Chemother. 33, 1066-

Woodford, N., Reynolds, R., Turton, J., Scott, F., Sinclair, A., Williams, A., Livermore, D., 2003. Two widely disseminated strains of Enterococcus faecalis highly resistant to gentamicin and ciprofloxacin from bacteraemias in the UK and Ireland. J Antimicrob. Chemother. 52, 711-714.

Worth, L.J., Slavin, M.A., Vankerckhoven, V., Goossens, H., Grabsch, E.A., Thursky, K.A., 2008. Virulence determinants in vancomycin-resistant Enterococcus faecium vanB: clonal distribution, prevalence and significance of esp and hyl in Australian patients with haematological disorders. J. Hosp. Infect. 68, 137-144.

Xu, X., Lin, D., Yan, G., Ye, X., Wu, S., Guo, Y., Zhu, D., Hu, F., Zhang, Y., Wang, F., Jacoby, G.A., Wang, M., 2010. vanM, a new glycopeptide resistance gene cluster found in Enterococcus faecium. Antimicrob. Agents Chemother. 54, 4643-4647.

Yoo, S.J., Sung, H., Cho, Y.U., Kim, M.N., Pai, C.H., Kim, Y.S., 2006. Role of horizontal transfer of the transposon Tn1546 in the nosocomial spread of vanA vancomycin- 
resistant enterococci at a tertiary care hospital in Korea. Infect. Control Hosp. Epidemiol. 27, 1081-1087.

Yoshimura, H., Ishimaru, M., Endoh, Y.S., Suginaka, M., Yamatani, S., 1998. Isolation of glycopeptide-resistant enterococci from chicken in Japan. Antimicrob. Agents Chemother. 42, 3333-

Young, H.L., Ballard, S.A., Roffey, P., Grayson, M.L., 2007. Direct detection of vanB2 using the Roche LightCycler vanA/B detection assay to indicate vancomycin-resistant enterococcal carriage - sensitive but not specific. J. Antimicrob. Chemother. 59, 809810.

Zarrilli, R., Tripodi, M.F., Di, P.A., Fortunato, R., Bagattini, M., Crispino, M., Florio, A., Triassi, M., Utili, R., 2005. Molecular epidemiology of high-level aminoglycosideresistant enterococci isolated from patients in a university hospital in southern Italy. J. Antimicrob. Chemother. 56, 827-835.

Zhanel, G.G., Calic, D., Schweizer, F., Zelenitsky, S., Adam, H., Lagace-Wiens, P.R., Rubinstein, E., Gin, A.S., Hoban, D.J., Karlowsky, J.A., 2010a. New lipoglycopeptides: a comparative review of dalbavancin, oritavancin and telavancin. Drugs 70, 859-886.

Zhanel, G.G., DeCorby, M., Adam, H., Mulvey, M.R., McCracken, M., Lagace-Wiens, P., Nichol, K.A., Wierzbowski, A., Baudry, P.J., Tailor, F., Karlowsky, J.A., Walkty, A., Schweizer, F., Johnson, J., Hoban, D.J., 2010b. Prevalence of antimicrobial-resistant pathogens in Canadian hospitals: results of the Canadian Ward Surveillance Study (CANWARD 2008). Antimicrob. Agents Chemother. 54, 4684-4693.

Zhanel, G.G., DeCorby, M., Laing, N., Weshnoweski, B., Vashisht, R., Tailor, F., Nichol, K.A., Wierzbowski, A., Baudry, P.J., Karlowsky, J.A., Lagace-Wiens, P., Walkty, A., McCracken, M., Mulvey, M.R., Johnson, J., Hoban, D.J., 2008a. Antimicrobialresistant pathogens in intensive care units in Canada: results of the Canadian National Intensive Care Unit (CAN-ICU) study, 2005-2006. Antimicrob. Agents Chemother. 52, 1430-1437.

Zhanel, G.G., DeCorby, M., Nichol, K.A., Baudry, P.J., Karlowsky, J.A., Lagace-Wiens, P.R., McCracken, M., Mulvey, M.R., Hoban, D.J., 2008b. Characterization of methicillinresistant Staphylococcus aureus, vancomycin-resistant enterococci and extendedspectrum beta-lactamase-producing Escherichia coli in intensive care units in Canada: Results of the Canadian National Intensive Care Unit (CAN-ICU) study (2005-2006). Can. J. Infect. Dis. Med. Microbiol. 19, 243-249.

Zhanel, G.G., Harding, G.K., Rosser, S., Hoban, D.J., Karlowsky, J.A., Alfa, M., Kabani, A., Embil, J., Gin, A., Williams, T., Nicolle, L.E., 2000. Low prevalence of VRE gastrointestinal colonization of hospitalized patients in Manitoba tertiary care and community hospitals. Can. J. Infect. Dis. 11, 38-41.

Zheng, B., Tomita, H., Inoue, T., Ike, Y., 2009. Isolation of VanB-type Enterococcus faecalis strains from nosocomial infections: first report of the isolation and identification of the pheromone-responsive plasmids pMG2200, Encoding VanB-type vancomycin resistance and a Bac41-type bacteriocin, and pMG2201, encoding erythromycin resistance and cytolysin (Hly/Bac). Antimicrob. Agents Chemother. 53, 735-747.

Zheng, B., Tomita, H., Xiao, Y.H., Ike, Y., 2007a. The first molecular analysis of clinical isolates of VanA-type vancomycin-resistant Enterococcus faecium strains in mainland China. Lett. Appl. Microbiol. 45, 307-312. 
Zheng, B., Tomita, H., Xiao, Y.H., Wang, S., Li, Y., Ike, Y., 2007b. Molecular characterization of vancomycin-resistant Enterococcus faecium isolates from mainland China. J. Clin. Microbiol. 45, 2813-2818.

Zhu, W., Clark, N.C., McDougal, L.K., Hageman, J., McDonald, L.C., Patel, J.B., 2008. Vancomycin-resistant Staphylococcus aureus isolates associated with inc18-like vanA plasmids in Michigan. Antimicrob. Agents Chemother. 52, 452-457.

Zhu, W., Murray, P.R., Huskins, W.C., Jernigan, J.A., McDonald, L.C., Clark, N.C., Anderson, K.F., McDougal, L.K., Hageman, J.C., Olsen-Rasmussen, M., Frace, M., Alangaden, G.J., Chenoweth, C., Zervos, M.J., Robinson-Dunn, B., Schreckenberger, P.C., Reller, L.B., Rudrik, J.T., Patel, J.B., 2010. Dissemination of an Enterococcus Inc18-like vanA plasmid, associated with vancomycin-resistant Staphylococcus aureus. Antimicrob. Agents Chemother.

Zhu, X., Zheng, B., Wang, S., Willems, R.J., Xue, F., Cao, X., Li, Y., Bo, S., Liu, J., 2009. Molecular characterisation of outbreak-related strains of vancomycin-resistant Enterococcus faecium from an intensive care unit in Beijing, China. J. Hosp. Infect. 72, 147-154.

Zirakzadeh, A., Patel, R., 2006. Vancomycin-resistant enterococci: colonization, infection, detection, and treatment. Mayo Clin. Proc. 81, 529-536.

Zirakzadeh, A., Patel, R., 2005. Epidemiology and mechanisms of glycopeptide reistance in enterococci. Current Opinion in Infectious Diseases 18, 507-512. 


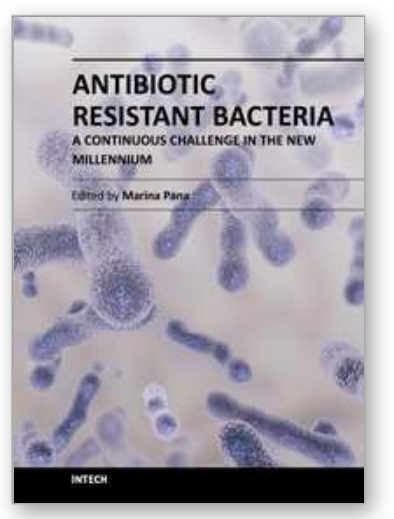

\section{Antibiotic Resistant Bacteria - A Continuous Challenge in the New Millennium}

Edited by Dr. Marina Pana

ISBN 978-953-51-0472-8

Hard cover, 576 pages

Publisher InTech

Published online 04, April, 2012

Published in print edition April, 2012

Antibiotic-resistant bacterial strains remain a major global threat, despite the prevention, diagnosis and antibiotherapy, which have improved considerably. In this thematic issue, the scientists present their results of accomplished studies, in order to provide an updated overview of scientific information and also, to exchange views on new strategies for interventions in antibiotic-resistant bacterial strains cases and outbreaks. As a consequence, the recently developed techniques in this field will contribute to a considerable progress in medical research.

\section{How to reference}

In order to correctly reference this scholarly work, feel free to copy and paste the following:

Guido Werner (2012). Current Trends of Emergence and Spread of Vancomycin-Resistant Enterococci, Antibiotic Resistant Bacteria - A Continuous Challenge in the New Millennium, Dr. Marina Pana (Ed.), ISBN: 978-953-51-0472-8, InTech, Available from: http://www.intechopen.com/books/antibiotic-resistant-bacteria-acontinuous-challenge-in-the-new-millennium/current-trends-of-emergence-and-spread-of-vancomycinresistant-enterococci

\section{INTECH}

open science | open minds

\section{InTech Europe}

University Campus STeP Ri Slavka Krautzeka 83/A 51000 Rijeka, Croatia Phone: +385 (51) 770447

Fax: +385 (51) 686166 www.intechopen.com

\section{InTech China}

Unit 405, Office Block, Hotel Equatorial Shanghai No.65, Yan An Road (West), Shanghai, 200040, China 中国上海市延安西路65号上海国际贵都大饭店办公楼405单元 Phone: +86-21-62489820

Fax: $+86-21-62489821$ 
(C) 2012 The Author(s). Licensee IntechOpen. This is an open access article distributed under the terms of the Creative Commons Attribution 3.0 License, which permits unrestricted use, distribution, and reproduction in any medium, provided the original work is properly cited. 